\title{
HEAT TRANSFER ANALYSIS FOR A FIXED CST COLUMN
}

Si Young Lee

Westinghouse Savannah River Company Savannah River Site

Aiken, SC 29808

Prepared for the U.S. Department of Energy Under Contract Number DEAC09-96SR18500

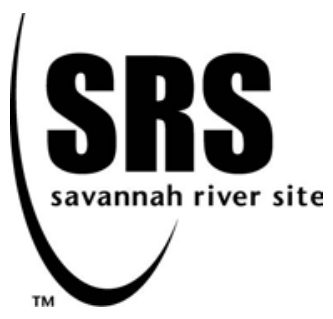


This document was prepared in conjunction with work accomplished under Contract No. DE-AC09-96SR18500 with the U. S. Department of Energy.

\section{DISCLAIMER}

This report was prepared as an account of work sponsored by an agency of the United States Government. Neither the United States Government nor any agency thereof, nor any of their employees, makes any warranty, express or implied, or assumes any legal liability or responsibility for the accuracy, completeness, or usefulness of any information, apparatus, product or process disclosed, or represents that its use would not infringe privately owned rights. Reference herein to any specific commercial product, process or service by trade name, trademark, manufacturer, or otherwise does not necessarily constitute or imply its endorsement, recommendation, or favoring by the United States Government or any agency thereof. The views and opinions of authors expressed herein do not necessarily state or reflect those of the United States Government or any agency thereof.

This report has been reproduced directly from the best available copy.

Available for sale to the public, in paper, from: U.S. Department of Commerce, National Technical Information Service, 5285 Port Royal Road, Springfield, VA 22161, phone: (800) 553-6847, fax: (703) 605-6900

email: orders@ntis.fedworld.gov

online ordering: http://www.ntis.gov/help/index.asp

Available electronically at http://www.osti.gov/bridge

Available for a processing fee to U.S. Department of Energy and its contractors, in paper, from: U.S. Department of Energy, Office of Scientific and Technical Information, P.O. Box 62, Oak Ridge, TN 37831-0062,

phone: (865)576-8401,

fax: (865)576-5728

email: $\underline{\text { reports@ adonis.osti.gov }}$ 
KEYWORDS:

Heat Transfer Model Numerical Approach

Transient Heat Transfer Model

Natural Convection

Heat Conduction

RETENTION - Permanent

\section{Heat Transfer Analysis For A Fixed CST Column}

SAVANNAH RIVER TECHNOLOGY CENTER

Si Young Lee

September 2003

Westinghouse Savannah River Company

Savannah River Site

Aiken, SC 29808

Prepared for the U.S. Department of Energy Under Contract Number DEAC09-96SR18500

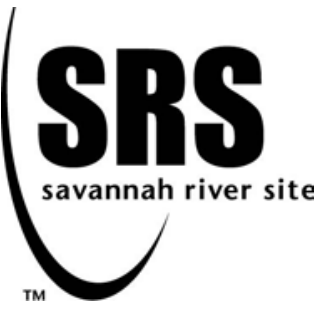


WSRC-TR-2003-00416

(This Page Intentionally Left Blank) 
(This Page Intentionally Left Blank) 
WSRC-TR-2003-00416

(This Page Intentionally Left Blank) 


\section{Table of Contents}

Acknowledgements $\quad$ vi

List of Figures vii

List of Tables $\quad$ ix

Nomenclature $\quad$ xi

$\begin{array}{ll}\text { Abstract } & 1\end{array}$

1 Introduction 2

2 Approach for the Heat Transfer Analysis of the CST Bed Column 2

2.1 General Governing Equations and Solution Method............................................ 5

2.2 Modeling Assumptions and Design Parameters ............................................ 13

3 Results and Discussions $\quad 18$

4 Conclusions $\quad 49$

6 References $\quad 51$ 
WSRC-TR-2003-00416

\section{Acknowledgements}

This work was performed under a NETL proposal in cooperation with SRTC and ORNL. The author is indebted to Dr. Darrel D. Walker who, as project coordinator, provided important modeling input and suggestions throughout the modeling work. He also wishes to acknowledge the contributions to some technical input provided by Mr. Dennis F. Bickford. 


\section{List of Figures}

Figure 1. Typical temperature profiles of CST packed bed column in energy transport process under natural/mixed convection cooling mode................................... 3

Figure 2. Basic designs considered for the present heat transfer analysis of the CST column

Figure 3. CST bed containing 100 to $500 \mathrm{Ci} /$ liter heat source and cooled by natural convection (Case-I design condition)

Figure 4. Modeling conditions and computational domain boundary for the present analysis of the 28 -in CST column with 6 -in sch. 40 pipe imbedded at its center (Case-III design condition)....

Figure 5. Adequacy of the grid fineness for the present analysis (Energy residual is defined by eq. (12)).

Figure 6. Two-dimensional computational meshes used for the present analysis.

Figure 7. Natural convection heat transfer correlation available in the literature showing the conservatism imbedded in the present analysis.

Figure 8. Forced convection correlation available in the literature for the heat transfer through the water-coolant system of the CST column.

Figure 9. Graphical illustration of the heat transfer model of the Case-I CST column under natural convection cooling.

Figure 10. Comparison of steady state results between the numerical computations and theoretical results for the Case-I type column under the reference conditions as defined in Table 4 (100 Ci/liter).....

Figure 10a. Comparison of steady state results between the numerical computations and theoretical results for the case-III type column under the reference conditions as defined in Table 4 (300 Ci/liter).

Figure 11. Comparison of steady state results for various heat sources of the CST-salt solution under the reference conditions ( 20 in column) as defined in Table 1 ...30

Figure 12. Transient temperature responses of CST column for 20 in column with different heat load under the reference conditions as defined in Table 1

Figure 13. Temperature contour plot for naturally-cooled CST-salt solution bed column with $300 \mathrm{Ci} /$ liter and $25^{\circ} \mathrm{C}$ ambient and initial temperatures at the transient time of 96 hours just as maximum temperature exceeds the boiling temperature (20-in column)

Figure 14. Comparison of steady state results for two different sizes of the CST columns under the reference conditions as defined in Table 4

Figure 15. Comparison of steady state results for various sizes of the CST columns under the reference conditions as defined in Table 4

Figure 16. Maximum and wall temperatures of CST column as function of heat loads for 20 in and 28 in columns under the reference conditions as defined in Table $4 \ldots 33$

Figure 17. Transient temperature responses of CST column for 36 in column with 100 $\mathrm{Ci} /$ /iter heat load under the reference conditions as defined in Table 4.

Figure 18. Comparison of temperature distributions for 26 -in column with 82 -in water jackets with $300 \mathrm{Ci} /$ liter heat load

Figure 19. Comparison of temperature distributions for 26 -in column with $300 \mathrm{Ci} / \mathrm{liter}$ heat load.

Figure 20. Comparison of temperature distributions for 26 -in column with $300 \mathrm{Ci} /$ liter heat load 
Figure 21. Maximum and wall temperatures as function of column diameter for 300 Ci/liter heat load

Figure 22. Temperature distributions for the annular column with $300 \mathrm{Ci} /$ liter heat load maintaining the volume of 26 -in cylindrical column (2-in void) $\left(T_{\max }=143^{\circ} \mathrm{C}\right) \ldots 38$

Figure 23. Temperature distributions for the annular column with $300 \mathrm{Ci} /$ liter heat load maintaining the volume of 26-in cylindrical column (3-in void) $\left(T_{\max }=133.5\right.$ $\left.{ }^{\circ} \mathrm{C}\right)$

Figure 24. Maximum temperatures for different sizes of center holes of the CST column maintaining the 26 -in column volume (300 Ci/liter)

Figure 25. Temperature distributions for the 28-in CST column with 6-in water-coolant pipe at its center $(300 \mathrm{Ci} /$ liter heat load $)\left(\mathrm{T}_{\max }=78{ }^{\circ} \mathrm{C}\right)$

Figure 26. Temperature distributions for the 28-in OD CST column with 6-in sch. 40 water-coolant pipe imbedded at its center and no water jacket on the column wall $(300 \mathrm{Ci} /$ liter heat load $)\left(\mathrm{T}_{\max }=133.4^{\circ} \mathrm{C}\right)$

Figure 27. Temperature distributions for various operating cases of the 28 -in CST columns of the Case-III and Case-IV designs loaded with $300 \mathrm{Ci} /$ liter volumetric heat source

Figure 28. Comparison of temperature distributions between the 4 and 8 water jacketed 28 -in CST columns imbedded with 6 -in pipe at its center $(300 \mathrm{Ci} /$ liter heat load)

Figure 29. Steady-state maximum temperature as function of heat load for 28 -in column under the two design conditions of 4 and 8 water jackets

Figure 30. Comparison of temperature distributions between two different designs of 28in CST columns imbedded with 6-in pipe at its center (300 Ci/liter heat load) .... 45

Figure 31. Transient temperature responses for 28 -in column with $300 \mathrm{Ci} /$ liter heat load under the Case-b design conditions.

Figure 32. Transient temperatures for 28 -in column loaded with $300 \mathrm{Ci} /$ liter under the Case-a design condition assuming that emergency water-jacket system is activated when maximum temperature of the CST column exceeds $100^{\circ} \mathrm{C}$ 
WSRC-TR-2003-00416

\section{List of Tables}

Table 1. Ranges of the operating and design conditions considered for the present heat transfer analysis of the CST column

Table 2. Material and thermal properties for the CST column heat transfer calculations. ...11

Table 3. Model conditions considered for the present coolability analysis of potential CST column designs under no flow condition. 15

Table 4. Modeling boundary conditions for the reference cases and sensitivity ranges of the present CST column designs under no flow condition. 16

Table 5. Heat source terms used for the present study [1] 16

Table 6. Comparison of the steady-state temperature responses with different heat loads between the two CST columns cooled by natural convection under the Case-I design defined by Fig. 2 (ambient temp. $=25^{\circ} \mathrm{C}$ ).

Table 7. Comparison of the steady state temperatures for three different ambient temperatures.

Table 8. Transient max. temperature results for the Case-I design under 20-in column with several different heat loads cooled by natural convection boundary.

Table 9. Steady-state maximum temperatures with the $300 \mathrm{Ci} /$ liter column cooled by mixed convection under the Case-III design defined by Fig. 2 (ambient temp. $=$ $35^{\circ} \mathrm{C}$ and water jacket temperature $=20^{\circ} \mathrm{C}$ ).

Table 10. Steady-state maximum temperatures with the $300 \mathrm{Ci} /$ liter column cooled by mixed convection under the Case-III design defined by Fig. 2 (ambient temp. = $35^{\circ} \mathrm{C}$ and water jacket temperature $=20^{\circ} \mathrm{C}$ ).

Table 11. Steady-state maximum temperatures with the $300 \mathrm{Ci} /$ liter column cooled by mixed convection under the Case-III design defined by Fig. 2 (ambient temp. $=$ $35^{\circ} \mathrm{C}$ and water jacket temperature $\left(\mathrm{T}_{\mathrm{wf}}\right)=20^{\circ} \mathrm{C}$ or $\left.30^{\circ} \mathrm{C}\right)$. 
WSRC-TR-2003-00416

(This Page Intentionally Left Blank) 
WSRC-TR-2003-00416

\section{Nomenclature}

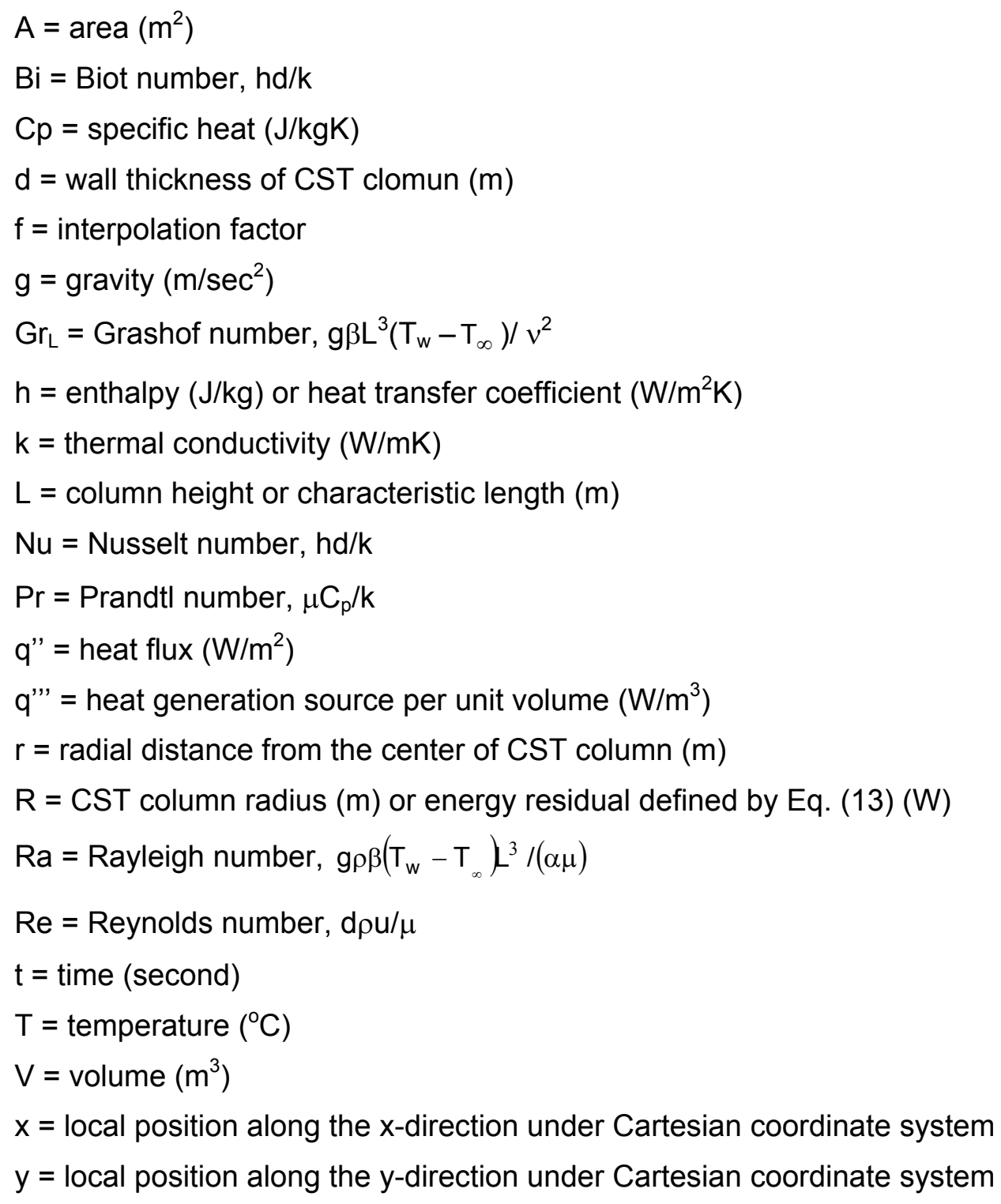




\section{Greek}

$\alpha=$ thermal diffusivity $\left(\mathrm{m}^{2} / \mathrm{sec}\right)$

$\beta=$ thermal expension coefficient $\left(\mathrm{K}^{-1}\right)$

$\rho=$ density $\left(\mathrm{kg} / \mathrm{m}^{3}\right)$

$\Delta=$ difference

$\mu=$ dynamic viscosity $\left(\mathrm{N} \mathrm{sec} / \mathrm{m}^{2}\right)$

$v=$ kinematic viscosity $\left(\mathrm{m}^{2} / \mathrm{sec}\right)$

$\theta=$ non-dimensional temperature

$\eta=$ non-dimensional radial diatance, $\mathrm{r} /(R+d)$

\section{Subscript}

$\mathrm{b}=$ bed

eff $=$ effective

$F=$ fuel

$\mathrm{i}=$ initial or interface

$L=$ length

$\max =$ maximum

$\mathrm{s}=$ inner wall surface of CST column

w or wall $=$ wall or wall boundary

wa = air contacted with column wall

$w f=$ water fluid contacted with column wall

$\infty=$ ambient 


\section{Abstract}

In support of a small column ion exchange (SCIX) process for the Savannah River Site waste processing program, a transient two-dimensional heat transfer model that includes the conduction process neglecting the convection cooling mechanism inside the crystalline silicotitanate (CST) column has been constructed and heat transfer calculations made for the present design configurations. For this situation, a no process flow condition through the column was assumed as one of the reference conditions for the simulation of a loss-of-flow accident. A series of the modeling calculations has been performed using a computational heat transfer approach.

Results for the baseline model indicate that transit times to reach $130^{\circ} \mathrm{C}$ maximum temperature of the CST-salt solution column are about 96 hours when the 20 -in CST column with $300 \mathrm{Ci} /$ liter heat generation source and $25^{\circ} \mathrm{C}$ initial column temperature is cooled by natural convection of external air as a primary heat transfer mechanism. The modeling results for the 28-in column equipped with water jacket systems on the external wall surface of the column and water coolant pipe at the center of the CST column demonstrate that the column loaded with $300 \mathrm{Ci} /$ liter heat source can be maintained non-boiling indefinitely.

Sensitivity calculations for several alternate column sizes, heat loads of the packed column, engineered cooling systems, and various ambient conditions at the exterior wall of the column have been performed under the reference conditions of the CST-salt solution to assess the impact of those parameters on the peak temperatures of the packed column for a given transient time. The results indicate that a water-coolant pipe at the center of the CST column filled with salt solution is the most effective one among the potential design parameters related to the thermal energy dissipation of decay heat load. It is noted that the cooling mechanism at the wall boundary of the column has significant impact on maximum and wall temperatures of the column. In addition, the results computed by the present model were verified by the theoretical results.

The analysis results will provide quantitative information associated with the process heat control and management of the CST base design. For example, transient responses of the CST system under a loss-of-flow accident condition will provide safety design information for an emergency cooling system of the column. 


\section{Introduction}

The small column ion exchange (SCIX) process treats low curie salt (LCS) waste before feeding it to the saltstone facility to be made into grout. Through this process, radioactive cesium from the salt solution is absorbed into the CST bed.

A CST column loaded with radioactive cesium will generate significant heat from radiolytic decay. If engineering designs of the CST sorption column can not handle this thermal load, hot spots may develop locally within the column and degrade the performance of the ion-exchange process. The CST starts to degrade at about 80 to $85^{\circ} \mathrm{C}$, and the CST completely changes to another material above $120^{\circ} \mathrm{C}$. In addition, the process solution will boil around $130^{\circ} \mathrm{C}$. If the column boiled dry, the sorbent could plug the column and require replacement of the column module.

The objective of the present work is to compute temperature distributions across the column as a function of transit time after the initiation of accidents when there is loss of the salt solution flow in the CST column under abnormal conditions of the process operations. In this situation, the customer requested that the calculations should be conservative in that the model results would show the maximum centerline temperatures achievable by the CST design configurations.

The thermal analysis results will be used to evaluate the fluid temperature distributions and the process component temperatures within the ion exchange system. This information will also assist in the system design and maintenance.

\section{Approach for the Heat Transfer Analysis of the CST Bed Column}

For the SCIX process, the design process rate requires a column bed with dimensions of $15 \mathrm{ft}$ long and 20 to 36 in diameter. A fully-loaded column may contain as much as 630 $\mathrm{Ci} /$ liter of $\mathrm{Cs}-137$. This highly concentrated radioactive source will generate a significant amount of heat in the column, which corresponds to about $12 \mathrm{~W} /$ gallon of volumetric heat source. Typical loadings are expected to be less than $300 \mathrm{Ci} /$ liter, which would generate about $6 \mathrm{~W} /$ gallon. Under normal operating conditions, process fluid flow through the column can provide adequate heat removal from the column through the conduction and convection coupled heat transfer mechanism. However, in the case of a loss of flow accident in the CST column, there are safety concerns about how fast the transient thermal response of the fully-loaded column is and how effectively the column is cooled down under the various design configurations.

For computational modeling purposes, a conservative approach is taken by assuming that the primary cooling mechanisms inside and outside of the column are conduction and natural convection, and axial heat removal from the column is negligible compared to that in the radial direction. A two-dimensional transient heat conduction model has been developed to assess the thermal performance of the CST column with loss of flow using the prototypic geometry. Figure 1 illustrates the heat transfer mechanism for the CST system configurations analyzed in this report. The model was created using the body-fitted coordinate system and structured multi-block grids in the Computational Fluid Dynamics (CFD) preprocessing environment. 


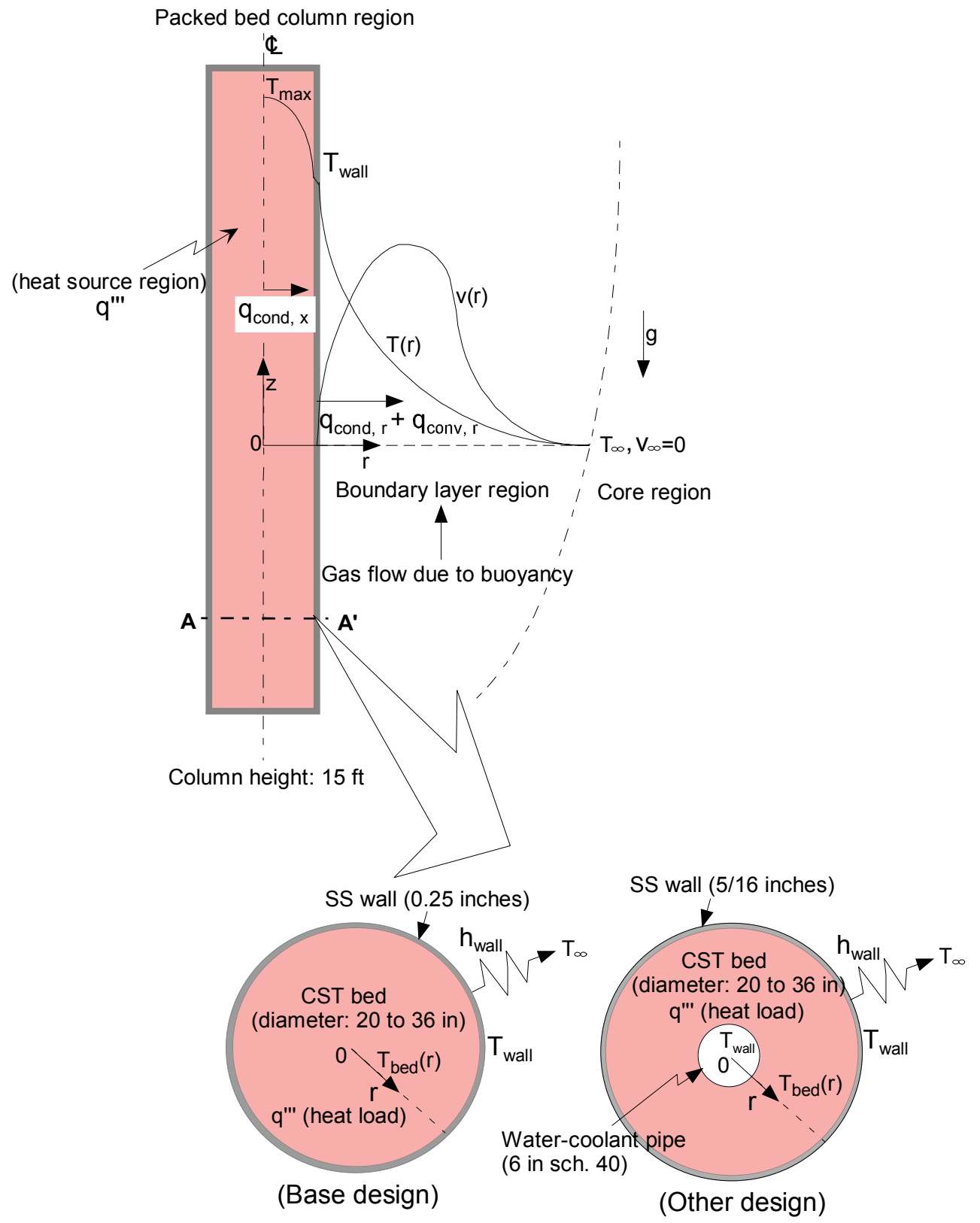

(A-A' cross-sectional plane)

Figure 1. Typical temperature profiles of CST packed bed column in energy transport process under natural/mixed convection cooling mode.

The model considers four basic cases with no process flow as shown Fig. 2. All the cases consider heat transfer by conduction for the bed column filled with salt solution. Heat transfer analysis of the CST column for the basic design cases is performed for a given boundary condition by using a computational heat transfer approach on a Cartesian $\mathrm{x}-\mathrm{y}$ grid under commercial CFD code, Fluent ${ }^{\mathrm{TM}}$, environment. The present modeling boundaries for heat transfer analyses of two CST column designs are shown in Fig. 3 and Fig. 4. One is a naturally-cooled CST column with passive cooling system 
such as the Case-I design (Fig. 3), and the other in the figure is the Case-III design equipped with forced convective cooling system (Fig. 4).

For heat transfer analysis, the reference design conditions were assumed as shown in Table 1. Spherical CST particles are packed inside a stainless steel cylinder that is 28 in diameter with $5 / 16$ inch thick wall as one of the reference conditions. Oak Ridge National Laboratory (ORNL) estimated the porosity of the CST packed bed is about 43.2 $\%$ [2]. The void volume fraction of the packed bed has a substantial impact on estimations of the thermal properties of a composite mixture. In the ORNL work, the bulk density of the CST column filled with salt solution was estimated to be about 1710 $\mathrm{kg} / \mathrm{m}^{3}$ considering that density of CST solid is $2,060 \mathrm{~kg} / \mathrm{m}^{3}$.

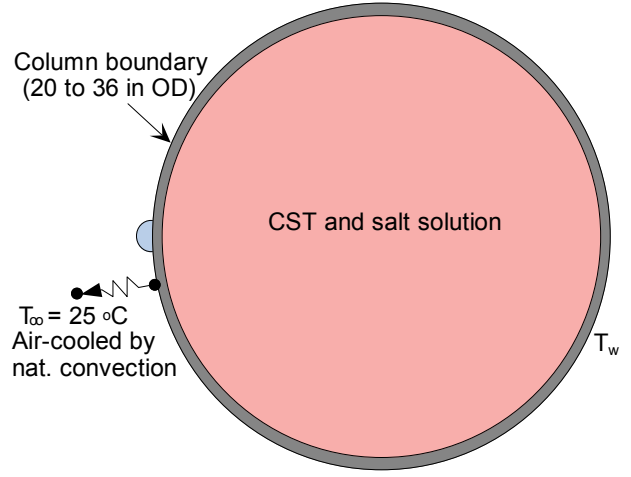

(Case-I)

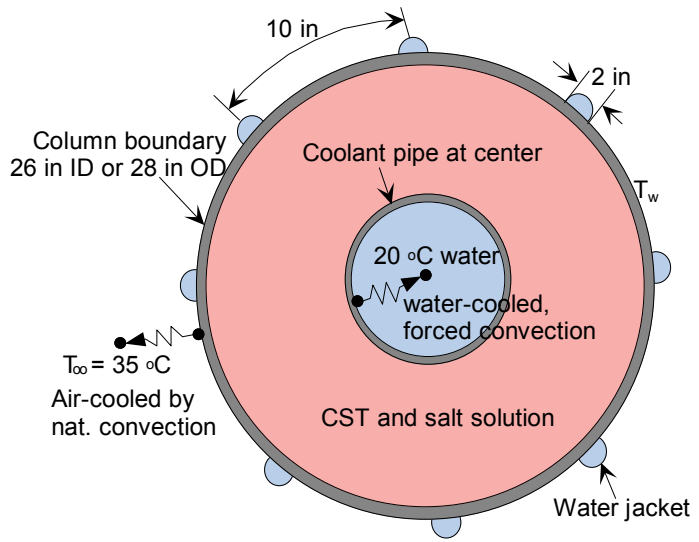

(Case-III)

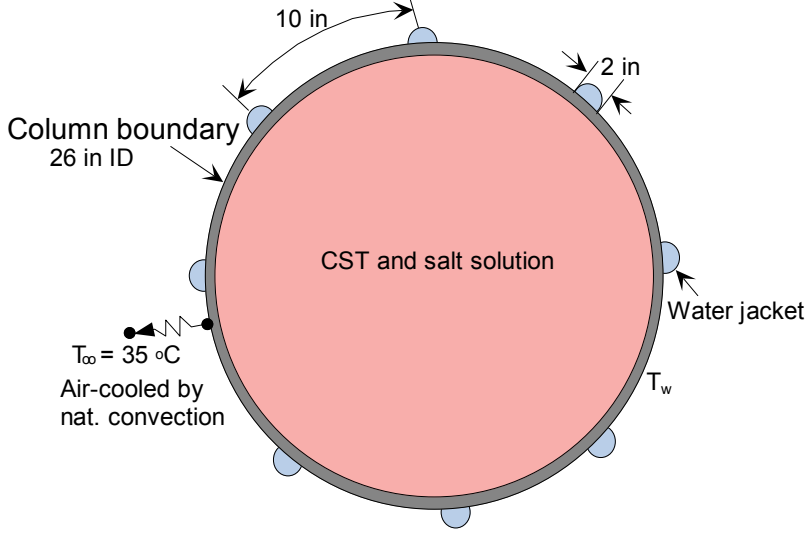

(Case-II)

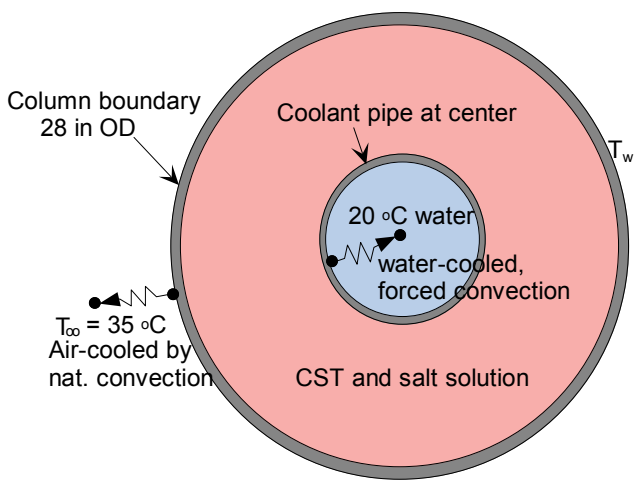

(Case-IV)

Figure 2. Basic designs considered for the present heat transfer analysis of the CST column 


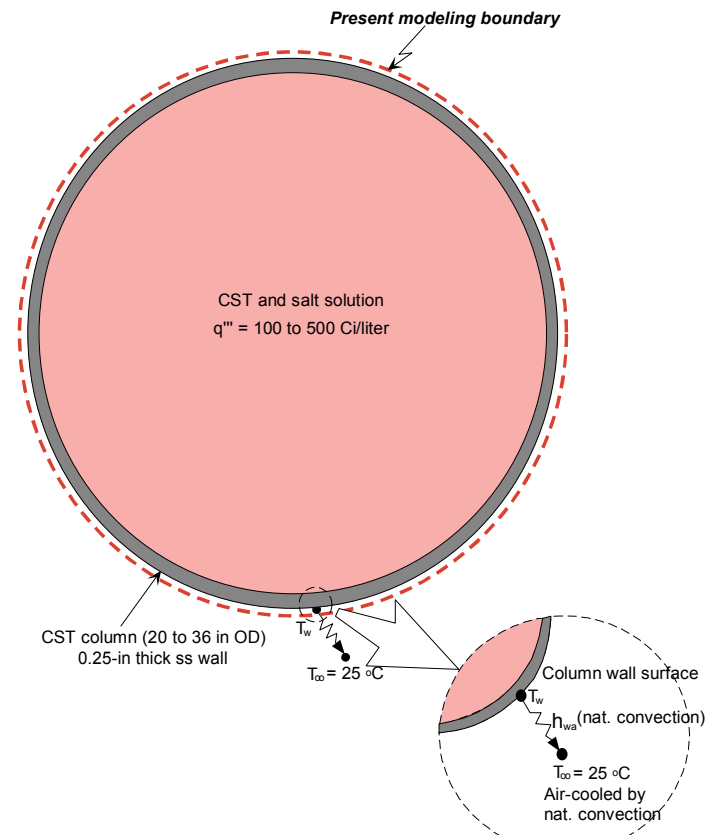

(Heat convection transferred into ambient air)

Figure 3. CST bed containing 100 to $500 \mathrm{Ci} /$ liter heat source and cooled by natural convection (Case-I design condition)

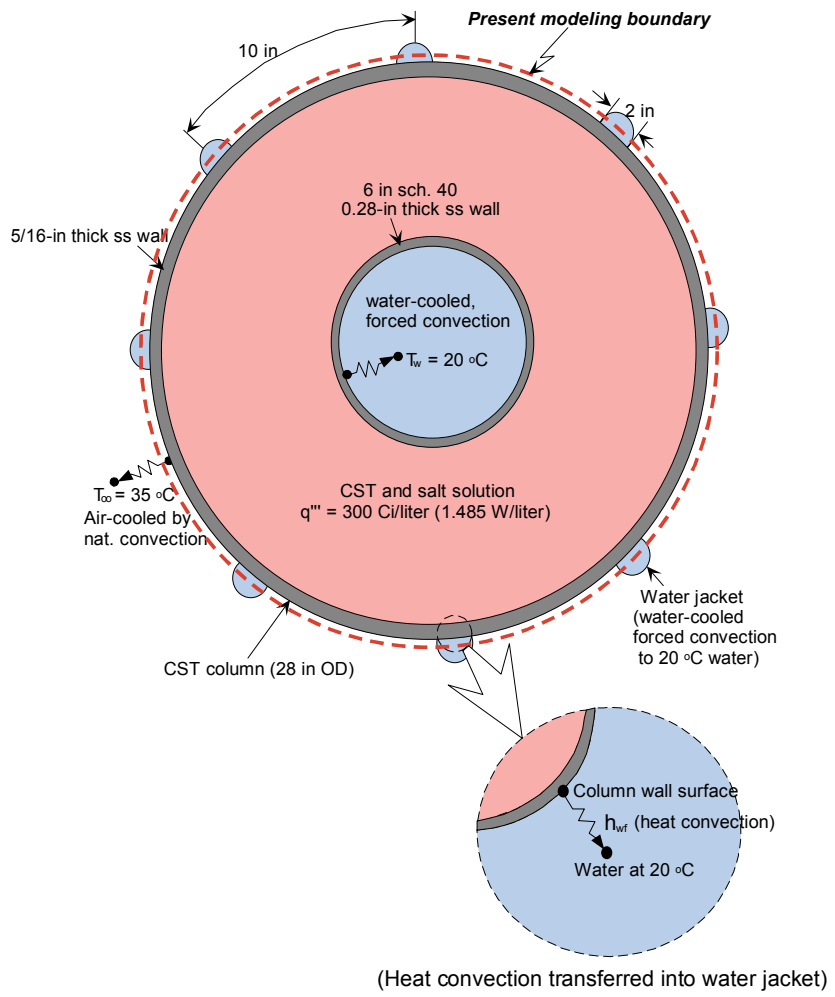

Figure 4. Modeling conditions and computational domain boundary for the present analysis of the 28-in OD CST column with 6-in sch. 40 pipe imbedded at its center (Case-III design condition) 
The temperature distributions inside a fixed CST bed with no process flow are computed for a conservative estimation of heat load in the column. For this work, a transient twodimensional heat conduction equation is applied to the modeling domain to examine heat control and management for various alternate column designs. Typical natural convection conditions available in the literature and the previous analysis are used at the boundary of the modeling domain. For the purpose of the analysis, the column is assumed to be an infinite cylinder (the ratio of the length to diameter is larger than 3 ) and the heat transfer effect along the axial direction is also assumed to be negligible compared to that of radial direction as discussed earlier. Effective composite thermal and material properties of the CST columns are obtained by using experimental values or empirical correlations available in the literature. When bulk properties of the bed composite properties such as density and specific heat are not available, they are estimated in terms of bed porosity assuming that they are homogeneously distributed.

For reference design conditions of the column, quasi-steady state temperature distributions are determined by taking a sequence of time steps from transient governing equations in an effort to understand how effectively the column heat is dissipated throughout the enclosure. Specifically, this investigation includes how long it takes to reach steady state or to reach the degradation temperature of the CST material when the Case-I column is cooled only by the natural convection mechanism without any forced convection cooling system or when the other alternate columns such as the Case-II to Case-IV designs are cooled by the mixed convection with engineered cooling system. Basic designs considered for the analysis are illustrated in Fig. 2. This information may be important to assess the performance of the operation and instrumentation for the CST ion exchange facility.

\subsection{General Governing Equations and Solution Method}

The CST column system contains a thin layer of stainless steel wall material surrounding the CST particles inside the column container. Void space of the column packed with CST beads will be filled with salt solution under no process flow situation during abnormal operating conditions. Schematic of the column system is shown in Fig. 1 [Ref. 1]. The column designs considered for the present work are shown in Fig. 2. Thermal and material properties for the CST and the column wall were obtained from the literature [Refs. 2, 5, and 10].

The heat generated by the system will be transferred by conduction through a twolayered medium and eventually will be transported to the ambient room through the physical processes of conduction and convection heat transport. The heat transfer rate at the solid-fluid interface boundary is computed using the fluid temperature gradient and heat transfer coefficient at the solid wall boundary with given ambient temperature. For the present work, the heat transfer coefficient will be estimated by the literature correlation.

When cooled by natural convection, the fluid temperature gradient depends on the gas flow field that is driven by the density gradient at the wall boundary layer and is dependent on the rate at which the gas fluid convects the heat away. Typical air flow and temperature profiles within the system containing the CST under actual energy transport process, including buoyancy-driven natural convection due to the fluid 
temperature gradient, were illustrated in the previous reports [5, 10]. Figure 1 illustrates buoyancy-driven natural convection caused by the fluid temperature gradient. Temperature decreases rapidly due to the convective cooling effect within a boundary layer region. The boundary layer flow is a buoyancy-induced motion, resulting from body forces acting on masses, which arise from temperature gradients in the fluid. It is virtually impossible to observe pure heat conduction in a gas medium because as soon as a temperature difference is imposed on a fluid, natural convection currents will occur as a result of force imbalances caused by density differences. Thus energy transport is coupled to the momentum transport through the wall interface of the solid and fluid regions, but in this case, ambient temperature and heat transfer coefficient at the solid wall will be assumed to be constant. This will lead to the reduction of computational time. In the previous work [4], sensitivity runs were performed to estimate conservatism imbedded in the assumptions.

The two-dimensional governing equations for the present analysis in the Cartesian coordinate system are shown below. For a general energy balance equation on a control segment of the CST column system,

$$
\rho \frac{\partial h}{\partial t}-\frac{\partial}{\partial x}\left\{k \frac{\partial T}{\partial x}\right\}-\frac{\partial}{\partial y}\left\{k \frac{\partial T}{\partial y}\right\}-q^{\prime \prime \prime}=0
$$

where $\mathrm{h}$ is enthalpy, and q"' heat generation source term per unit volume. Heat source term is included in the present model since significant amount of decay heat is generated from the ion exchange process through the CST bed column.

In eq. (1), energy terms within a control volume of a solid medium in the column include conduction $(k \nabla T)$ and energy storage due to transients $\left(\rho \not h / \partial t=\rho C_{p} \partial T / \partial t\right)$. In this situation, radiation and convection terms in the energy balance equation were neglected since solid phase in the column is continuously contacted each other and fluid phase temperature is primarily maintained below boiling temperature. $k$ in equation (1) is thermal conductivity of the medium in the computational domain. This property value will be provided by the constitutive relation later. The CST column with volumetric heat source q"' will be cooled down by natural convection process through its wall surface as shown in Fig. 1. In this case, when wall boundary and initial conditions are provided, the governing equations are complete. They are

$-(k \nabla T)_{\text {wall }}=h_{w}\left(T-T_{\infty}\right)_{\text {wall }}$

and

$T(t=0)=T_{i}$

In eq. (2), $h_{w}$ and $T_{\infty}$ are wall heat transfer coefficient and ambient temperature, respectively. $T_{i}$ in eq. (3) is initial temperature of the computational domain.

Heat transfer coefficient at the outside wall of the CST column $\left(h_{w}\right)$ is obtained by using the empirical correlation available in the literature. As reference condition for the present work, the column is assumed to be cooled by the natural convection. In this situation, natural convection flow regime for the air-cooled design should be estimated based on the non-dimensional Grashof number $\left(\mathrm{Gr}_{\mathrm{L}}\right)$, which is the parameter describing the ratio of buoyancy to viscous forces for vertically-oriented cylinder with height $L$. The Grashof number performs much the same function for natural convection flow as the 
Reynolds (Re) number does for forced convection. Under normal conditions one may expect that the laminar-to-turbulent transition will take place at about $\mathrm{Gr}_{L} \approx 10^{9}$.

For a typical air-cooled system without forced air circulation,

$$
G r_{L}=\frac{g \beta L^{3}\left(T_{w}-T_{\infty}\right)}{v_{f}^{2}}
$$

where $L=$ characteristic length parameter $(=4.8768 \mathrm{~m})$,

$$
\begin{aligned}
& \beta=\text { thermal expansion coefficient }\left(=3.34 \times 10^{-3} \mathrm{~K}^{-1}\right), \\
& v_{f}=\left(\mu_{f} / \rho_{f}\right)=\text { kinematic fluid viscosity }\left(=3.80 \times 10^{-5} \mathrm{~m}^{2} / \mathrm{sec}\right) .
\end{aligned}
$$

In eq. (4), Grashof number was estimated as about $10^{9}$ for about $20^{\circ} \mathrm{C}$ temperature difference at wall to examine the boundary layer flow regime of natural convection. This corresponds to the turbulent flow according to the literature information [7].

For the present analysis, natural convection regime around the CST column is assumed to be turbulent. As shown in Fig. 1, geometrical configurations for the present analysis are vertically-oriented cylindrical column. However, literature results [8] show that when geometrical ratio of diameter $(D)$ to height $(L)$ are greater than or equal to $35\left(G r_{L}\right)^{-0.25}$, natural convection correlation for vertical flat-plate can be applied to vertical cylinder equally. For the present configurations of the 28-in column,

$$
\left(\frac{D}{L}\right)=0.156>\left(35 G_{L}^{-0.25}\right) \approx 0.056
$$

Warner and Arpaci (1968) performed an experimental investigation of turbulent natural convection in air from a vertical heated plate. The results of this study showed good agreement with the following correlation for Grashof number up to $10^{12}$ :

$$
N u_{L}=\left(\frac{h_{w} L}{k_{f}}\right)=0.10\left(\operatorname{Pr}_{f} G r_{L}\right)^{1 / 3}
$$

where $\operatorname{Pr}_{f}$ is Prandtl number and

$$
\operatorname{Pr}_{f}=\frac{\mu_{f} C p_{f}}{k_{f}}
$$

In eq. (6) all material properties should be evaluated at the mean fluid temperature of $T_{f}=0.5\left(T_{w}+T_{\infty}\right)$, and $h_{w}$ is natural convection heat transfer coefficient at the heated solid wall. $k_{f}$ is thermal conductivity of fluid at the fluid temperature $T_{f}$.

These governing equations are applied to the two-dimensional computation domain depending on the physical model for the heat transfer analysis of the CST column assuming that the axial heat transfer of the column is negligible. There is heat source information ( $q$ "' in eq. (1)) for the CST column region. For conservative heat transfer calculations, the heat source was estimated for fully-loaded and uniformly-distributed CST bed. The current calculations used a range of heat loads (100 to $500 \mathrm{Ci} /$ liter), corresponding to 495 to $2475 \mathrm{~W} / \mathrm{m}^{3}$, as volumetric heat source q"' in the energy equation as shown in Table 1 [1]. In addition, this region was included as a conduction 
zone and was assumed as constant thermal conductivity instead of temperaturedependent thermal property to the energy equation of the CST-salt solution column since the thermal conductivity of the material increases linearly with temperature. Effective thermal conductivity of the CST-salt column was used from the experimental correlation developed by ORNL [2].

Table 1. Ranges of the operating and design conditions considered for the present heat transfer analysis of the CST column.

\begin{tabular}{|c|c|}
\hline Parameters & Ranges of parameter values \\
\hline Initial temperature & 25 to $35^{\circ} \mathrm{C}$ for the entire computational domain \\
\hline Ambient temperature & 25 to $35^{\circ} \mathrm{C}$ \\
\hline Heat transfer coefficient at wall & $\begin{array}{r}1.5 \mathrm{~W} / \mathrm{m}^{2} \mathrm{sec} \text { (typical natural convection) to mixed } \\
\text { convection (for high heat loaded column) }\end{array}$ \\
\hline Column diameter & 20 to 36 in OD (5/16 in thick) \\
\hline Heat load & 100 to $500 \mathrm{Ci} /$ liter (0.495 to 2.475 watts/liter) $[1]$ \\
\hline Fluid inside the CST column & Salt solution \\
\hline Granular bed conditions & Fixed bed \\
\hline Bed hydraulic conditions & No flow condition \\
\hline Bed porosity & $43.2 \%$ \\
\hline
\end{tabular}

The material and thermal properties for the components of the CST packed column system are provided in Table 2. Using these thermal properties, a two-dimensional transient conduction model was performed to find transient thermal response of the CST fixed bed region in case of the loss of the CST process flow. For computational efficiency, effective thermal conductivity for the composite column region was used. Effective thermal conductivity of the CST bed region was estimated by the literature correlation [12]. That is, effective thermal conductivity of the bed ( $\left.k_{b, e f f}\right)$ was developed as function of the bed porosity $\varepsilon$ in SI unit $(\mathrm{W} / \mathrm{mK})$ using the literature experimental data.

$k_{b, \text { eff }}=k_{f}\left(\frac{k_{p}}{k_{f}}\right)^{A+B \log \left(\frac{k_{p}}{k_{f}}\right)}$

where

$$
A=0.280-0.757 \log \varepsilon \text { and } B=-0.057 .
$$

In eq. (8), $k_{p}$ and $k_{f}$ are thermal conductivities of CST particle and fluid inside the bed column, respectively. Coefficient $A$ is a function of the bed porosity. The thermal conductivity of the CST particle $\left(k_{p}\right)$ is assumed to be constant for conservative estimation and computational efficiency. 
Date: $\quad 12 / 8 / 2003$

Page: $\quad 10$ of 52

Effective material properties of the CST column filled with salt solution or air are computed in terms of the column porosity $\varepsilon$. Effective density $\rho_{b, \text { eff }}$ and specific heat $C p_{b, \text { eff }}$ of the bed column are based on homogeneous assumption. That is,

$\rho_{b, \mathrm{eff}}=\varepsilon \rho_{f}+(1-\varepsilon) \rho_{C S T}$

$C p_{b, \text { eff }}=\varepsilon C p_{f}+(1-\varepsilon) C p_{C S T}$

In eqs. (10) and (11), subscripts $f$ and CST are referred to as fluid and CST materials, respectively. Thus, computational time can be reduced by modeling a single-material region with the effective thermal conductivity instead of modeling multi-material region composed of two different materials. This leads to the reduction of the computational time and effort.

The two-dimensional geometry file was created using the multi-block preprocessor of the Fluent ${ }^{\mathrm{TM}}$ code [3] under the body-fitted coordinate system, which allows the treatment of non-orthogonal geometry. The present model consists of 5 element blocks and 2 different material zones on the $x-y$ computational plane. Non-uniform two-dimensional structured meshes of the computational domain were used to capture the smooth temperature gradient across the boundary zone of the two different material regions. Typical modeling boundaries for the Case-I and Case-III designs are shown in Fig. 3 and Fig. 4, respectively. Numerical solution technique to solve the governing equations was described in Reference [4, 6].

The overall energy balance should be checked to demonstrate the adequacy of the grid fineness used. This was done by using eq. (12).

$$
R=-\int_{A_{W}} q_{W}^{\prime \prime} d A+q^{\prime \prime \prime} V_{F}
$$

Volumetric heat source term, q'", in eq. (12) is given by the code input. For all the cases considered here, energy residual $(R)$ is less than about 1 watt. For instance, the residual results for the case of the CST-salt solution bed are shown as function of grid number in Fig. 5. For the present analysis, an optimum grid of about 16660 cells for the Case-I design has been established from the grid sensitivity analysis under IBM workstation environment. Nonuniform two-dimensional meshes used for the computational analysis of the Case-I and Case-III columns are shown in Fig. 6. 
WESTINGHOUSE SAVANNAH RIVER COMPANY

HEAT TRANSFER ANALYSIS FOR A FIXED CST COLUMN
Report:WSRC-TR-2003-00416

Date:

$12 / 8 / 2003$

Page:

11 of 52

Table 2. Material and thermal properties for the CST column heat transfer calculations.

\begin{tabular}{|c|c|c|c|}
\hline Material & $\begin{array}{c}\text { Thermal conductivity } \\
(\mathrm{W} / \mathrm{mK})\end{array}$ & $\begin{array}{c}\text { Density } \\
(\mathrm{kg} / \mathrm{m} 3)\end{array}$ & $\begin{array}{c}\text { Specific heat } \\
(\mathrm{J} / \mathrm{kgK})\end{array}$ \\
\hline CST-Salt Solution & $0.2836^{\#}$ & $1710.3^{* *}$ & $2165.9^{* *}$ \\
\hline Salt Solution [13] & 0.68 & 1255.4 & 3630.0 \\
\hline Stainless steel [14] & 17.30 & 7800.0 & 486.0 \\
\hline
\end{tabular}

Note: * $\mathrm{T}$ in ${ }^{\circ} \mathrm{C}$

\# based on non-linear empirical correlation of Krupiczka (1967) at $25^{\circ} \mathrm{C}$ temperature [12]

** based on the condition that volume fraction of fluid or air in packed bed is 0.432 at $25^{\circ} \mathrm{C}$ temperature 
Report: WSRC-TR-2003-00416

Date: $\quad 12 / 8 / 2003$

Page: $\quad 12$ of 52

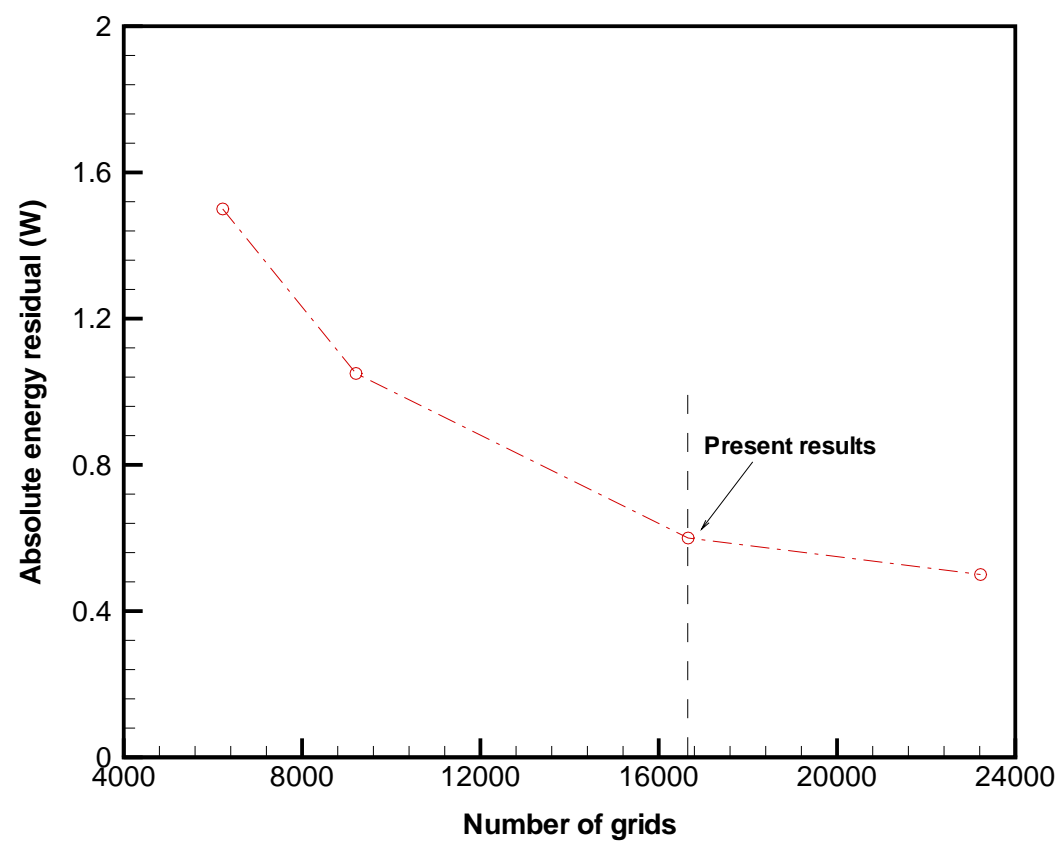

Figure 5. Adequacy of the grid fineness for the present analysis (Energy residual is defined by eq. (12)).

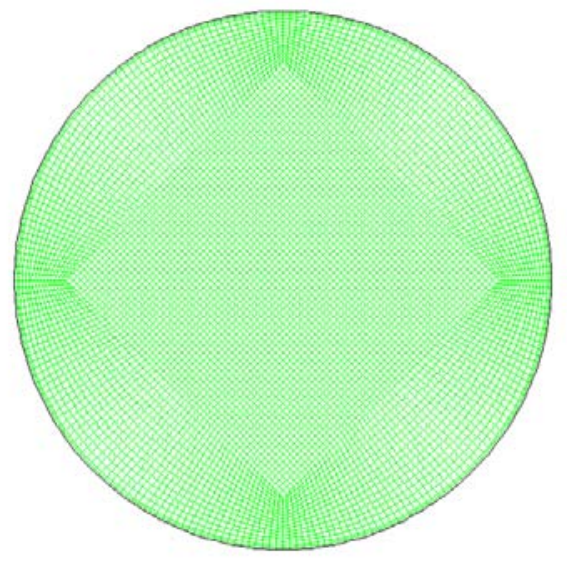

(Base model: Case-I)

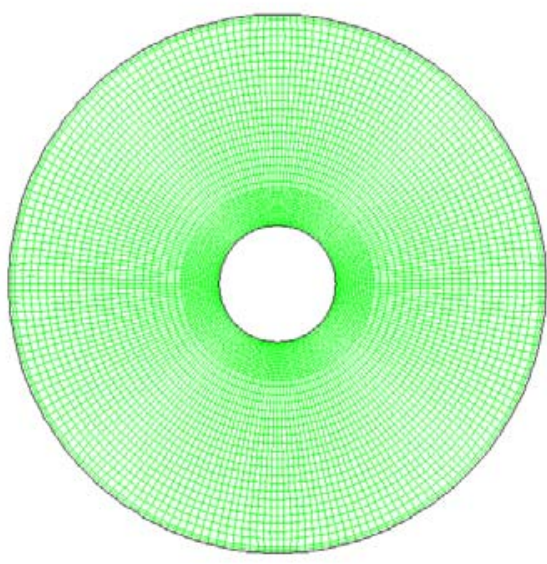

(Model for Case-III design)

Figure 6. Two-dimensional computational meshes used for the present analysis. 


\subsection{Modeling Assumptions and Design Parameters}

The present analyses are made for the heat transfer calculations of a CST ion exchange column. The computational modeling domain is shown in Fig. 2. A conservative approach was taken to estimate transient temperature profiles of a fully-loaded CST column with no process fluid flow. In this situation, the column with heat source was assumed to be cooled only by a typical natural convection mechanism.

The present computations used the following main assumptions:

- Column is filled with a fixed bed of CST particles and salt solution.

- Cell ambient temperature is constant $\left(25^{\circ} \mathrm{C}\right.$ or $\left.35^{\circ} \mathrm{C}\right)$.

- Columns are assumed to be filled with one of two no-flow scenarios. One column consists of CST and salt solution (CST-salt solution), and the other is the column filled with CST and air (CST-air). Both of them have $25^{\circ} \mathrm{C}$ initial temperatures for the purpose of transient system evaluations.

- Outside the column there is no forced convective airflow, so natural convection is the primary heat transfer mechanism from the exterior of the CST column wall. Radiative cooling contributions at the inner and outer wall surfaces of the column are conservatively assumed to be negligible.

- The heat source $\left({ }^{137} \mathrm{Cs}\right.$ and ${ }^{137 \mathrm{~m}} \mathrm{Ba}$ decay) is uniformly distributed throughout the entire bed of the CST column and produces $1.485 \mathrm{~W} /$ /iter assuming that the column is loaded to $300 \mathrm{Ci} /$ liter.

A typical natural convective heat transfer coefficient $\left(h_{w}\right)$ of $1.5 \mathrm{~W} / \mathrm{m}^{2} \mathrm{~K}$ was used as an external wall boundary condition for the present analysis. The present value of the heat transfer coefficient can be justified on the following basis:

For a conservative calculation, low temperature gradient at the wall boundary layer was used to estimate natural convection capability for the present geometrical configurations. Heat transfer coefficient $\left(h_{w}\right)$ for natural convective cooling under turbulent flow regime $\left(\mathrm{Ra}_{f}=G r_{L} P r_{f}>10^{9}\right)$ is given in terms of non-dimensional numbers empirically.

$N u_{L}=\frac{h_{w} L}{k_{w}}=C\left(G r_{L} \operatorname{Pr}_{f}\right)^{m} \quad$ for $\operatorname{Gr}_{L} \operatorname{Pr}_{f}<10^{12}$

where $\mathrm{C}$ and $\mathrm{m}$ are the coefficients determined by the literature data. $L$ is characteristic length of the CST column.

For the present geometrical configuration, $\mathrm{C}=0.10$ and $\mathrm{m}=0.333$ are given by Warner and Arpaci (1968) using the experimental data [10]. From eq. (13), heat transfer coefficient $\left(h_{w}\right)$ is about $1.5 \mathrm{~W} / \mathrm{m}^{2} \mathrm{~K}$ corresponding to $N u_{L} \approx 260$ conservatively under the present conditions. Figure 7 shows the quantified results for the literature correlation based on turbulent natural convection, which was developed by Warner and Aparci (1968). The figure shows the conservatism imbedded in the present modeling conditions for the natural convection through the wall surface of the CST column containing the decay heat source. In the previous work [11], wall heat transfer driven by natural convection was also evaluated by using boundary layer theory.

Heat transfer coefficient $\left(h_{w f}\right)$ for forced convective heat transfer mechanisms through the column wall attached to the water jackets and through the inner surface of the 
coolant pipe at the column center were estimated by Dittus-Boelter's correlation [14]. That is,

$$
N u_{d}=\frac{h_{w f} d_{h}}{k_{w f}}=0.023\left(\operatorname{Re}_{d}\right)^{0.8}\left(\operatorname{Pr}_{w f}\right)^{a} \text { for } R e_{d}>2000
$$

Equation (14) is applicable to turbulent flow when Reynolds number is larger than 2,000 in terms of hydraulic diameter, and the parameter $a$ in eq. (14) is 0.4 when the fluid is heated as modeled in the present work. Reynolds number for the present study is about 30,000 when $16 \mathrm{gpm}$ flowrate of water flows in 2-in half-moon type of coolant tube corresponding to $1 \mathrm{~m} / \mathrm{sec}$ flow velocity. In the present work, three basic cases including forced convection case are considered to perform the heat transfer analysis for key design parameters of the CST column as shown in Table 3. Forced convection heat transfer coefficients at the water jackets $\left(h_{w f}\right)$ attached to the exterior of the column wall and at the inner surface of 6 -in water pipe were estimated by eq. (14). From the CST reference design, wall heat transfer coefficient governed by forced convection mechanism was estimated as $h_{w f}=268\left(\mathrm{~W} / \mathrm{m}^{2} \mathrm{~K}\right)$ for the wall surface of 6 -in coolant pipe and $h_{w f}=3790\left(\mathrm{~W} / \mathrm{m}^{2} \mathrm{~K}\right)$ for the wall of 2 -in water jacket. Figure 8 shows quantified results for the present modeling conditions in terms of Reynolds number.

The main design parameters involved for the heat transfer in a fixed bed CST column under no flow conditions are as follows:

- Ambient cell temperature around the CST column system

- Heat load of the CST column

- External and internal heat removal conditions of the CST column such as coolant pipe size and flow conditions

Table 4 presents modeling boundary conditions for the base cases and sensitivity ranges of the present CST column designs under no flow condition. Table 5 shows a range of the potential heat loads due to the Cs absorption into the CST material during normal operation. 
Table 3. Model conditions considered for the present coolability analysis of potential CST column designs under no flow condition.

\begin{tabular}{|c|c|c|c|c|}
\hline \multirow{2}{*}{ Parameters } & \multicolumn{4}{|c|}{ CST-Salt Solution Column } \\
\hline & $\begin{array}{c}\text { Case-I } \\
\text { (Base case) }\end{array}$ & Case-II & Case-III & Case-IV \\
\hline $\begin{array}{l}\text { Column-filled } \\
\text { fluid }\end{array}$ & Salt sol. & Salt sol. & Salt sol. & Salt sol. \\
\hline $\begin{array}{c}\text { Column } \\
\text { diameter } \\
\text { considered }\end{array}$ & 20 to 36 in OD & 26 in ID & $\begin{array}{l}26 \text { in ID and } 28 \text { in OD } \\
\text { (mainly } 28 \text { in OD) }\end{array}$ & 28 in OD \\
\hline $\begin{array}{l}\text { Cooling } \\
\text { mechanism }\end{array}$ & Nat. convection & Mixed convection* & Mixed convection* & Mixed convection* \\
\hline $\begin{array}{l}\text { Cooling } \\
\text { system }\end{array}$ & $\begin{array}{l}\text { Passive system } \\
\text { (naturally } \\
\text { cooled) }\end{array}$ & $\begin{array}{c}8 \text { or } 4 \text { Water } \\
\text { jackets at the } \\
\text { external wall of } \\
\text { column }\end{array}$ & $\begin{array}{l}\text { Water jacket at } \\
\text { external column wall } \\
\text { and coolant pipe at } \\
\text { center ( } 2 \text { to } 6 \text { in } \\
\text { diameter) }\end{array}$ & $\begin{array}{c}\text { No water jacket at } \\
\text { external column } \\
\text { wall and water- } \\
\text { cooled 6-in pipe at } \\
\text { center }\end{array}$ \\
\hline $\begin{array}{c}\text { Heat loads } \\
\text { considered } \\
\text { (Ci/liter) }\end{array}$ & 100 to 500 & 300 & $\begin{array}{c}100 \text { to } 500 \\
(\text { Nominal load }=300)\end{array}$ & 300 \\
\hline $\begin{array}{c}\text { Ambient } \\
\text { temperature }\end{array}$ & $25^{\circ} \mathrm{C}$ & $25^{\circ} \mathrm{C}$ to $45^{\circ} \mathrm{C}$ & $35^{\circ} \mathrm{C}$ & $35^{\circ} \mathrm{C}$ \\
\hline $\begin{array}{c}\text { Water } \\
\text { coolant temp. }\end{array}$ & None & $20^{\circ} \mathrm{C}$ & $20^{\circ} \mathrm{C}$ and $30^{\circ} \mathrm{C}$ & $20^{\circ} \mathrm{C}$ \\
\hline
\end{tabular}

Note: * Natural heat transfer coefficient at the exterior wall of the CST column, and forced convection $\left(h_{w f}\right)$ for water jacket wall and coolant pipe surface evaluated by Dittus-Boelter correlation, eq. (14) 
Report: WSRC-TR-2003-00416

Date: $\quad 12 / 8 / 2003$

Page: $\quad 16$ of 52
WESTINGHOUSE SAVANNAH RIVER COMPANY

HEAT TRANSFER ANALYSIS FOR A FIXED CST COLUMN

Table 4. Modeling boundary conditions for the reference cases and sensitivity ranges of the present CST column designs under no flow condition.

\begin{tabular}{|c|c|}
\hline \multirow{2}{*}{ Parameters } & CST-Salt Solution Column \\
\cline { 2 - 3 } & Reference case (sensitivity range) \\
\hline Column size & 20 in for Case-I (20 to 36 in), 26 in for Case-II, \\
28 in for Case-III and -IV
\end{tabular}

Note: * heat transfer coefficient at the exterior wall of the CST column

Table 5. Heat source terms used for the present study [1]

\begin{tabular}{|c|c|c|c|}
\hline \multicolumn{4}{|c|}{ Volumetric heat source } \\
\hline Ci/liter & watts/liter & watts/gal & watts/f $^{3}$ \\
\hline 100 & 0.495 & 1.87 & 14.02 \\
\hline 200 & 0.990 & 3.75 & 28.03 \\
\hline $300^{*}$ & $1.485^{\star}$ & $5.62^{*}$ & $42.05^{\star}$ \\
\hline 400 & 1.980 & 7.50 & 56.07 \\
\hline 500 & 2.475 & 9.36 & 70.08 \\
\hline
\end{tabular}

Note: * Reference case for the heat-loaded CST column 


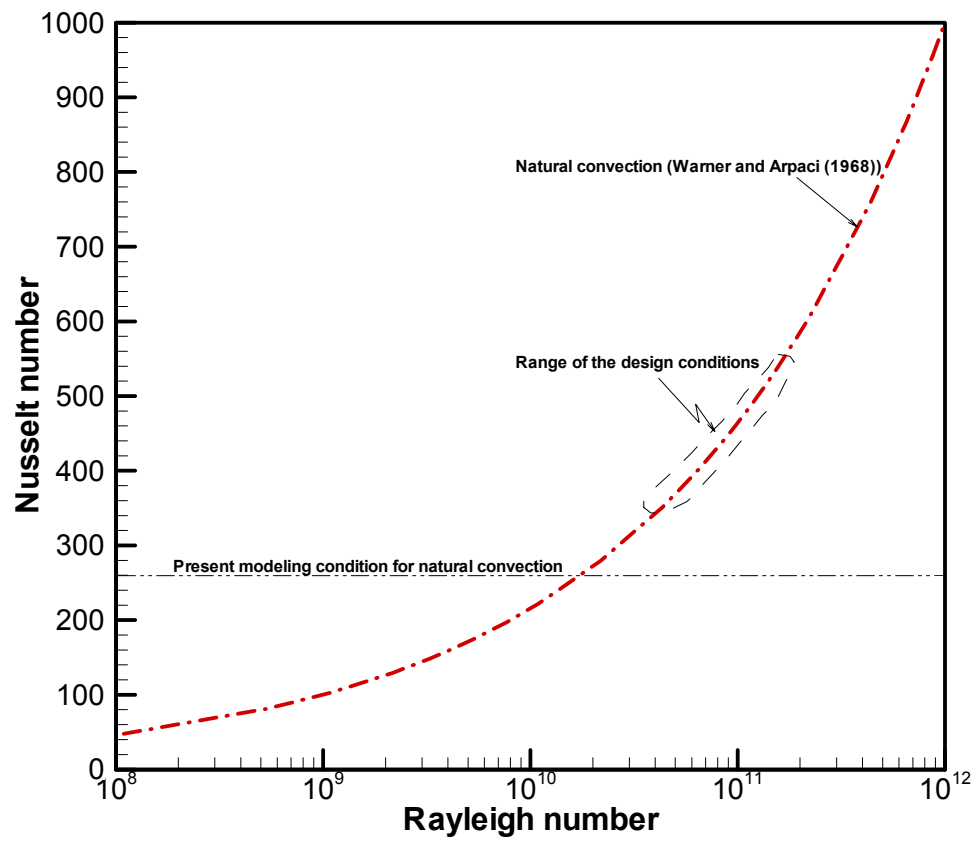

Figure 7. Natural convection heat transfer correlation available in the literature showing the conservatism imbedded in the present analysis.

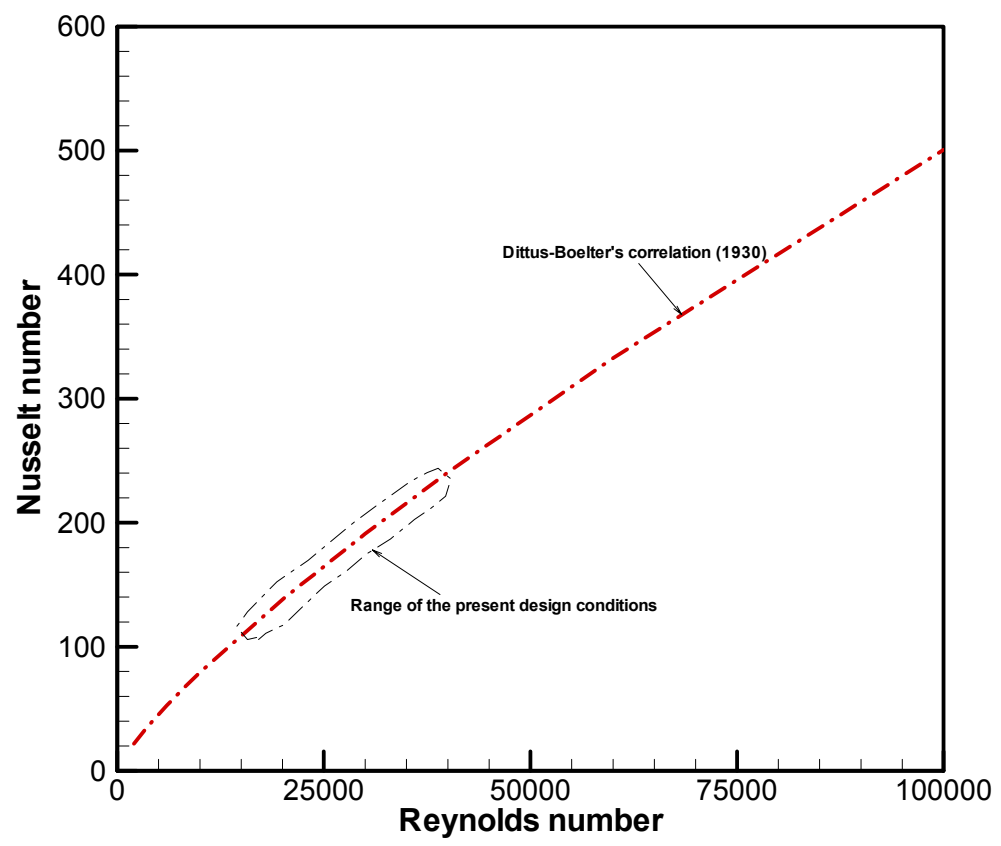

Figure 8. Forced convection correlation available in the literature for the heat transfer through the water-coolant system of the CST column. 


\section{Results and Discussions}

Based on the approach methodology and the modeling assumptions, a two-dimensional analysis has been performed to compute temperature distributions within the modeling boundary shown in Figs. 3 and 4 and to investigate transient temperature response to decay heat load of the CST column with no process flow. This column is assumed to be cooled primarily by natural convection under the basic design conditions defined by Table 3. The thermal and material properties of the column components including the CST particle are shown in Table 2. Detailed dimensions for the CST design configurations are shown in Fig. 2 as modeled in the present analysis. The computational heat transfer approach has been taken by using a commercial finite volume code, Fluent ${ }^{\mathrm{TM}}$ [3], as a tool to create prototypic geometry file under nonorthogonal mesh environment in the body-fitted coordinate system and to solve the governing equations (eqs. (1) through (3)) by considering transient conduction cooling process with convection boundary conditions. As shown in Fig. 5, optimum number of meshes was obtained by sensitivity analysis of grid fineness. Figure 6 presents twodimensional computational meshes used for the present analysis.

A theoretical approach for steady-state conduction heat transfer of the multi-layered cylinder with heat generation source in a natural convection was taken to verify the present computational model under the present geometrical and physical conditions as shown in Fig. 9. The theoretical model was based on one-dimensional approach. Under steady-state conditions, the energy equation (1) for the CST packed column with effective thermal conductivity $k_{b, \text { eff }}$ becomes

$k_{b, \text { eff }} \nabla^{2} T+q^{\prime \prime \prime}=0$

For the CST column region with uniform heat generation source q"' as shown in Fig. 8, eq. (15) becomes

$$
\frac{d^{2} T}{d r^{2}}+\frac{1}{r} \frac{d T}{d r}+\frac{q^{\prime \prime \prime}}{k_{b, \text { eff }}}=0
$$

As boundary conditions, the following relations at the center and wall of the CST column are applied to the above equation, eq. (16).

$$
\begin{aligned}
& \left.\frac{d T}{d r}\right|_{r=0}=0 \\
& T(r=R)=T_{s}
\end{aligned}
$$

After integrating eq. (16) and applying the boundary conditions, radial temperature distribution for the CST column region with heat generation source q"' becomes

$$
T(r)=T_{s}+\frac{q^{\prime \prime \prime}}{4 k_{b, \text { eff }}}\left(R^{2}-r^{2}\right) \quad(0 \leq r \leq R)
$$

Equations governing the stainless wall region $(R \leq r \leq(R+d))$ with no heat source $(q " '=0)$ are

$$
\frac{d^{2} T}{d r^{2}}+\frac{1}{r} \frac{d T}{d r}=0
$$


Boundary conditions at the wall of the column are

$T(r=(R+d))=T_{w}$

and

$q_{w}^{\prime \prime}=-\left.k_{w} \frac{d T}{d r}\right|_{r=(R+d)}=h_{w}\left(T_{w}-T_{\infty}\right)$.

where $\mathrm{d}$ is the stainless steel wall thickness of the CST column, and $k_{w}$ is thermal conductivity of stainless steel wall.

In eq. (22) wall heat flux $\left(q_{w}^{\prime \prime}\right)$ can be obtained by the energy balance between heat source and heat sink when volumetric heat source q"' is spatially uniform in Region-I of Fig. 8. The resulting equation for the wall heat flux is

$q_{w}^{\prime \prime}=q^{\prime \prime \prime}\left(\frac{V_{b}}{A_{w}}\right)=q^{\prime \prime \prime}\left\{\frac{\pi R^{2} L}{2 \pi(R+d) L}\right\}=q^{\prime \prime \prime}\left\{\frac{R^{2}}{2(R+d)}\right\}$

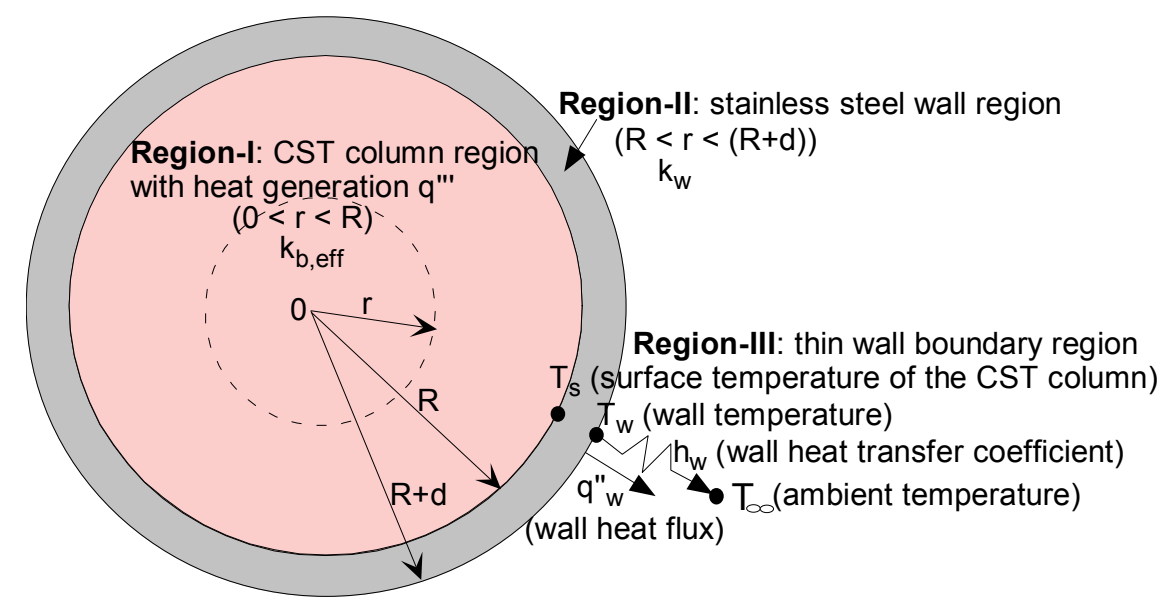

Figure 9. Graphical illustration of the heat transfer model of the Case-I CST column under natural convection cooling.

Using eqs. (21), (22), and (23), radial temperature distribution of the CST wall region with no heat source $(q " \prime=0)$ becomes

$$
\begin{array}{rlrl}
T(r) & =T_{w}+\frac{q_{w}^{\prime \prime}(R+d)}{k_{w}} \ln \left(\frac{R+d}{r}\right) & \\
& =T_{w}+\frac{q^{\prime \prime \prime} R^{2}}{2 k_{w}} \ln \left(\frac{R+d}{r}\right) \quad(R \leq r \leq(R+d))
\end{array}
$$

Surface temperature can be evaluated by eq. (24). That is,

$$
T_{s}=T_{w}+\frac{q^{\prime \prime \prime} R^{2}}{2 k_{w}} \ln \left(\frac{R+d}{R}\right)
$$


Wall surface temperature of the CST column ( $\left.T_{w}\right)$ can be obtained by eqs. (22) and (23) at $r=(R+d)$ in terms of convection heat transfer coefficient $\left(h_{w}\right)$ at the wall surface of the column and ambient temperature $\left(T_{\infty}\right)$ of Region-III shown in Fig. 9.

$$
\begin{aligned}
T_{w} & =T_{\infty}+\frac{q^{\prime \prime}{ }_{w}}{h_{w}} \\
& =T_{\infty}+\frac{q^{\prime \prime \prime}}{2 h_{w}}\left(\frac{R^{2}}{R+d}\right)
\end{aligned}
$$

From eqs. (19), (25), and (26), center temperature of the CST-fluid bed region can be obtained in terms of natural convection boundary condition and ambient temperature.

$$
T(r=0)=T_{\infty}+\left(\frac{q^{\prime \prime \prime} R^{2}}{2}\right)\left\{\frac{1}{h_{w}(R+d)}+\frac{1}{k_{w}} \ln \left(\frac{R+d}{R}\right)\right\}+\frac{q^{\prime \prime \prime}}{4 k_{b, \text { eff }}} R^{2}
$$

The temperature distribution for each region can be non-dimensionalized in terms of the column wall temperature difference $\left(T_{w}-T_{\infty}\right)$ and the column radius $(\mathrm{R}+\mathrm{d})$ to examine the impacts of the design parameters on the CST temperature distributions. Nondimensional parameters shown in Fig. 10 are defined as follows:

$$
\eta=\frac{r}{(R+d)} \text { and } \theta=\left(\frac{T-T_{\infty}}{T_{w}-T_{\infty}}\right)
$$

Temperature and length scales are non-dimensionalized in terms of the column temperature difference $\left(T_{w}-T_{\infty}\right)$ and the column radius $(\mathrm{R}+\mathrm{d})$ as shown in eq. (28).

For region-I $(0 \leq \eta \leq R /(R+d)$, non-dimensional temperature distribution can be obtained from eqs. (19), (25), (26), and (28).

$$
\theta(\eta)=1+\frac{B i}{2} \ln \left(\frac{R+d}{R}\right)+\frac{B i}{4}\left(\frac{k_{w}}{k_{b, \text { eff }}}\right)\left\{1-\left(\frac{R+d}{R}\right)^{2} \eta^{2}\right\}
$$

Biot number $(\mathrm{Bi})$ in eq. (29) is defined as the ratio of convection at wall surface to conduction through the column wall region. That is

$$
B i=\frac{h_{w} D}{k_{w}}=\frac{2(R+d) h_{w}}{k_{w}}
$$

Thus, the Biot number compares the relative magnitudes of surface convection and internal conduction resistance to heat transfer. A very low value of the Biot number means that internal conduction resistance is negligible in comparison with surface convection resistance. This in turn implies that the temperature will be nearly uniform throughout the conduction media.

Non-dimensional temperature distribution for the region-II $(R /(R+d) \leq \eta \leq 1)$ can be obtained from eqs. (24) and (28).

$$
\theta(\eta)=1-\frac{B i}{2} \ln \eta
$$


From eq. (29) maximum temperature of the CST column with thin wall thickness under steady-state condition becomes

$$
\theta_{\text {max }} \approx 1+\frac{B i}{4}\left(\frac{k_{w}}{k_{b, \text { eff }}}\right)
$$

Thus, non-dimensional temperature distributions inside the CST column and wall regions can be computed, and they can be compared with the steady-state numerical results to verify the model predictions. In this case, the numerical solution was obtained by solving transient governing equations with a sequence of time steps until steady-state solution is reached. Eq. (32) shows that the maximum temperature gradient is closely related to the wall Biot number and the ratio of thermal conductivity of the column wall region to effective thermal conductivity of the composite CST column. For a given geometry and wall cooling conditions, effective thermal conductivity is found to be the key parameter to control the maximum temperature difference between the column center and its wall.

It took about 70 days for the CST-salt solution column to reach steady-state solutions starting with transient governing equations with $25^{\circ} \mathrm{C}$ initial uniform temperature under the reference conditions. Slow transient thermal response of the column to the heat load of $100 \mathrm{Ci} /$ liter is mainly due to the large heat capacity of the back-filled fluid such as salt solution. Comparisons of theoretical values with the present computational results are made for the verification of the present calculations as shown in Fig. 10. In this case, the steady-state temperature differences for the CST-salt solution columns between the column center and wall are about $27{ }^{\circ} \mathrm{C}$ for the 20 -in column, about $88{ }^{\circ} \mathrm{C}$ for the 36 -in column, respectively, assuming that material and thermal properties of the column system remain constant and volumetric heat load is $100 \mathrm{Ci} /$ liter. It is shown that the present computational results are in good agreement with theoretical results within about $0.01 \%$.

For the enhanced cooling capability of the fully-loaded column design, the case-III type column with the coolant pipe imbedded at its center was chosen. Steady-state temperature distributions within the Case-III-type column containing uniform heat load q"' were obtained by using a theoretical approach. When temperature boundary conditions are provided at the inner and outer wall boundaries of the 28-in column with volumetric heat source q"' under the same governing equation as the Case-I geometry, eq. (15). The resulting equation of the temperature distribution $T(r)$ at a radial position $r$ from the column center becomes

$$
T(r)=T_{\text {wi }}-\frac{q^{\prime \prime \prime}\left(r^{2}-R_{i}{ }^{2}\right)}{4 k_{b, \text { eff }}}+\left[\frac{q^{\prime \prime \prime}}{4 k_{b, \text { eff }}}\left(R_{o}{ }^{2}-R_{i}{ }^{2}\right)-\left(T_{\text {wi }}-T_{\text {wo }}\right)\right]\left(\frac{\ln \left(r / R_{i}\right)}{\ln \left(R_{0} / R_{i}\right)}\right)
$$

In eq. (33) the parameters $R_{o}$ and $R_{i}$ the inner and outer radii, and $T_{w i}$ and $T_{\text {wo }}$ are the inner and outer wall temperatures, respectively.

The theoretical temperature distributions were compared with the modeling results for the 28-in Case-III-type column with $300 \mathrm{Ci} /$ liter corresponding to $1.485 \mathrm{~W} /$ liter. The validated results are shown in Fig. 10a.

Table 8 shows transient temperature results for various heat loads at the center of the 20 -in CST column (base case of the Case-I column geometry) as function of transient 
time under the reference conditions defined in Table 4. The results show that maximum temperature of the 20-in CST-salt column loaded with $500 \mathrm{Ci} /$ liter reaches boiling temperature in about 2 days. Steady-state temperature distributions of the column are compared for five different heat loads in Fig. 11. The results demonstrate that the naturally-cooled 20-in column of the Case-I type design can be loaded with at most 160 $\mathrm{Ci} /$ liter decay source without any local boiling when ambient cell temperature is kept 25 ${ }^{\circ} \mathrm{C}$ during no flow condition. Table 7 shows sensitivity results for the column temperature due to the variation of ambient temperatures. The results show that when ambient temperature varies from $25{ }^{\circ} \mathrm{C}$ to $45^{\circ} \mathrm{C}$, maximum temperature of the CST-salt column increases by about $20^{\circ} \mathrm{C}$ as expected.

Transient thermal responses of the 20-in column to different decay heat loads are compared in Fig. 12. Temperature contour plot for the naturally-cooled column with 300 $\mathrm{Ci} /$ liter heat load is shown in Fig. 13. The results in the figure show that the 20-in column loaded with $300 \mathrm{Ci} /$ liter can reach boiling condition in about 4 days from the 25 ${ }^{\circ} \mathrm{C}$ of the initial CST temperature during no process flow when cooled by natural convection.

As shown in Fig. 14, comparison of steady state results for two different sizes of the Case-I type CST columns are made under the reference conditions as defined in Table 4. When a column loaded with $100 \mathrm{Ci} /$ iter source is cooled by natural convection, the column size can be designed to be at most 27 in to satisfy the allowable temperature limit. That is, maximum temperature of the CST column can not exceed the boiling temperature of $130^{\circ} \mathrm{C}$ under any operating conditions. The results are shown in Fig. 15. When a Case-I type column is cooled by natural convection, maximum temperatures for two different column diameters 20 in and 28 in are presented as function of decay heat loads in Fig. 16. Table 6 compares steady-state temperature responses with different heat loads between the two different column sizes of the Case-I design. Maximum and wall temperatures for the 20-in Case-I column loaded with $100 \mathrm{Ci} /$ liter are shown for different ambient temperatures in Table 7.

It is noted that maximum temperature for a given column size increases linearly with the heat load increase when the column uses passive cooling mode with no engineered cooling system. In this case, the column diameter can not exceed 27 in without boiling when it is loaded with $100 \mathrm{Ci} /$ liter. Figure 17 shows transient temperature responses of the largest CST column (36 in diameter) considered for the present study when it is loaded with $100 \mathrm{Ci} /$ liter decay heat under the reference conditions as defined in Table 4. As mentioned earlier, the process solution will boil around $130{ }^{\circ} \mathrm{C}$. It takes about 12 days for the CST-salt column (Case-I) to reach that boiling temperature under the same reference conditions. The transient results are summarized in Table 8.

All modeling results demonstrated that an engineered cooling system is required to preclude boiling $\left(<130{ }^{\circ} \mathrm{C}\right.$ ) of a $300 \mathrm{Ci} /$ liter column for the current size range of the Case-I type column, 20 to 36 in diameter. Thus, the Case-Il column design with external cooling jacket, as shown in Fig. 2, is considered to avoid boiling condition during no process flow. This design has 8 water jackets attached to the external wall surface of the Case-I type column with about 10-in separation distance between jackets for a 26 -in column (Fig. 3). Each water jacket consists of 2-in half-moon shaped tube along the vertical direction, and it is assumed to maintain a constant bulk fluid temperature by using a heat exchanger. 
Table 6. Comparison of the steady-state temperature responses with different heat loads between the two CST columns cooled by natural convection under the Case-I design defined by Fig. 2 (ambient temp. $=25^{\circ} \mathrm{C}$ ).

\begin{tabular}{|c|c|c|c|}
\hline \multicolumn{2}{|c|}{ Column designs for Case-I } & 20 in column & 28 in column \\
\hline \multirow{2}{*}{$100 \mathrm{Ci} /$ liter } & Wall temp. & 64.9 & 81.5 \\
\cline { 2 - 4 } & Center temp. & 91.5 & 134.5 \\
\hline \multirow{2}{*}{$200 \mathrm{Ci} /$ iter } & Wall temp. & 104.7 & 138.1 \\
\cline { 2 - 4 } & Center temp. & 158.0 & 243.9 \\
\hline \multirow{2}{*}{$300 \mathrm{Ci} /$ iter } & Wall temp. & 144.5 & 194.6 \\
\cline { 2 - 4 } & Center temp. & 224.5 & 353.4 \\
\hline
\end{tabular}

Table 7. Comparison of the steady state temperatures for three different ambient temperatures.

\begin{tabular}{|c|c|c|c|}
\hline \multirow{2}{*}{ Cases $^{*}$} & \multicolumn{3}{|c|}{ Ambient temperature } \\
\cline { 2 - 4 } & $25^{\circ} \mathrm{C}$ & $35^{\circ} \mathrm{C}$ & $45^{\circ} \mathrm{C}$ \\
\hline Effective thermal conductivity $(\mathrm{W} / \mathrm{mK})$ & \multicolumn{3}{|c|}{0.2836} \\
\hline Thermal diffusivity $\left(\mathrm{cm}^{2} / \mathrm{sec}\right)$ & \multicolumn{3}{|c|}{$7.66 \times 10^{-4}$} \\
\hline Heat load (Ci/liter) [W/liter] & \multicolumn{3}{|c|}{$100[0.495]$} \\
\hline Wall heat transfer coeff. $\left(h_{w}\right)$ & $1.5 \mathrm{~W} / \mathrm{m}^{2} \mathrm{~K}($ natural convection) \\
\hline Max. Temperature & $92^{\circ} \mathrm{C}$ & $102^{\circ} \mathrm{C}$ & $112^{\circ} \mathrm{C}$ \\
\hline Column wall temperature & $65^{\circ} \mathrm{C}$ & $75^{\circ} \mathrm{C}$ & $85^{\circ} \mathrm{C}$ \\
\hline
\end{tabular}

Note: * the cases considered for 20 in column 
Report: WSRC-TR-2003-00416

WESTINGHOUSE SAVANNAH RIVER COMPANY

Date: $\quad 12 / 8 / 2003$

Page: $\quad 24$ of 52

HEAT TRANSFER ANALYSIS FOR A FIXED CST COLUMN

Table 8. Transient max. temperature results for the Case-I design under 20-in column with several different heat loads cooled by natural convection boundary.

\begin{tabular}{|c|c|c|c|c|}
\hline \multirow{2}{*}{$\begin{array}{c}\text { Transient time } \\
\text { (hours) }\end{array}$} & \multicolumn{4}{|c|}{ CST-Salt solution Column $\left({ }^{\circ} \mathrm{C}\right.$ ) } \\
\cline { 2 - 5 } & $100 \mathrm{Ci} /$ liter & $200 \mathrm{Ci} /$ liter & $300 \mathrm{Ci} /$ liter & $500 \mathrm{Ci} /$ liter \\
\hline Initial condition & 25.0 & 25.0 & 25.0 & 25.0 \\
\hline 0.5 & 25.3 & 25.5 & 25.7 & 26.2 \\
\hline 1 & 25.5 & 26.0 & 26.5 & 27.4 \\
\hline 4 & 26.9 & 28.9 & 30.8 & 34.6 \\
\hline 8 & 28.9 & 32.7 & 36.6 & 44.2 \\
\hline 10 & 29.8 & 34.6 & 39.4 & 49.0 \\
\hline 16 & 32.6 & 40.3 & 47.9 & 63.3 \\
\hline 32 & 39.8 & 54.4 & 68.8 & 99.5 \\
\hline 48 & 45.6 & 66.7 & 88.7 & 131.5 \\
\hline
\end{tabular}

The nominal operating conditions of the water jacket system for the present study include fluid flowrate in each jacket and coolant temperature of about $16 \mathrm{gpm}$ corresponding to $1 \mathrm{~m} / \mathrm{sec}$ and coolant temperature of $20^{\circ} \mathrm{C}$, respectively. The detailed modeling conditions for the Case-II model are provided in Table 4. The temperature contour plot for this case is shown in Fig. 18 for a 26-in column with $300 \mathrm{Ci} /$ liter heat load and $35{ }^{\circ} \mathrm{C}$ ambient temperature. It is noted that maximum temperature is about 40 ${ }^{\circ} \mathrm{C}$ higher than the boiling temperature. The calculation results show that the water jacket system is very effective in reducing maximum temperature of the CST column by about $150{ }^{\circ} \mathrm{C}$ over the naturally-cooled column, but the center temperature of the column still exceeds the boiling temperature. The results for the two case designs, Case-I and Case-II, are compared in Fig. 19. Sensitivity results for the number of water jackets show that when the number of water jackets is increased to 16 instead of 8 , the column temperature is reduced by about $5{ }^{\circ} \mathrm{C}$ (Fig. 20). Figure 21 shows maximum center temperature and minimum wall temperature of the column when it is loaded with 300 $\mathrm{Ci} /$ liter using the reference conditions as defined in Table 4 . It is evident that peak temperature of the CST column exceeds boiling temperature when the Case-II column size is larger than 23 inches in diameter.

As alternative design, the Case-III design (Fig. 4) was considered as a viable option. In this case a water or air coolant pipe is penetrated through the center of the column in addition to the water jacket system at the column wall to enhance heat removal of the heat-loaded column during no process flow. Temperature distributions for the 26-in column imbedded with 2 in and 3 in empty pipe at the column center are shown in Fig. 22 and Fig. 23, respectively, when ambient temperatures for the central air region and 
the column cell are assumed to be $35{ }^{\circ} \mathrm{C}$. Figure 24 shows maximum column temperature as a function of the air-filled pipe size penetrated through the center of the column (Case-III column as shown in Fig. 2) when the CST volume maintains the same as that of the 26-in Case-I column with $300 \mathrm{Ci} /$ liter decay heat and ambient air temperature is $35^{\circ} \mathrm{C}$. In this case an air-filled pipe at least 3.5 in diameter is required at the center of the column to keep the maximum column temperature below $130{ }^{\circ} \mathrm{C}$. The modeling results for different sizes of the empty pipe are quantitatively compared in Table 9.

When the pipe has $16 \mathrm{gpm}$ water flowrate instead of natural convection, maximum temperature of the 26 -in column loaded with $300 \mathrm{Ci} /$ liter heat source is $72{ }^{\circ} \mathrm{C}$, which is about $42{ }^{\circ} \mathrm{C}$ lower than the air-filled case. The results are compared in Table 9. From the Case-I and Case-III results, as shown in Fig. 16 and Table 10, the final column design shown in Fig. 4 has been established in terms of the column coolability and the waste process requirement. The present heat transfer analysis indicates that the 28-in column design with water jackets at the wall boundary and 6-in water pipe at the column center prevents boiling of the liquid phase during an extended no-flow accident. In this analysis water coolant temperature was assumed to be constant, but the actual heatingup of water was found to be small (about less than $1^{\circ} \mathrm{C}$ ).

Table 9. Steady-state maximum temperatures with the $300 \mathrm{Ci} /$ liter column cooled by mixed convection under the Case-III design with the 26 -in ID column volume (ambient temp. $=35^{\circ} \mathrm{C}$ and water jacket temperature $=20^{\circ} \mathrm{C}$ ).

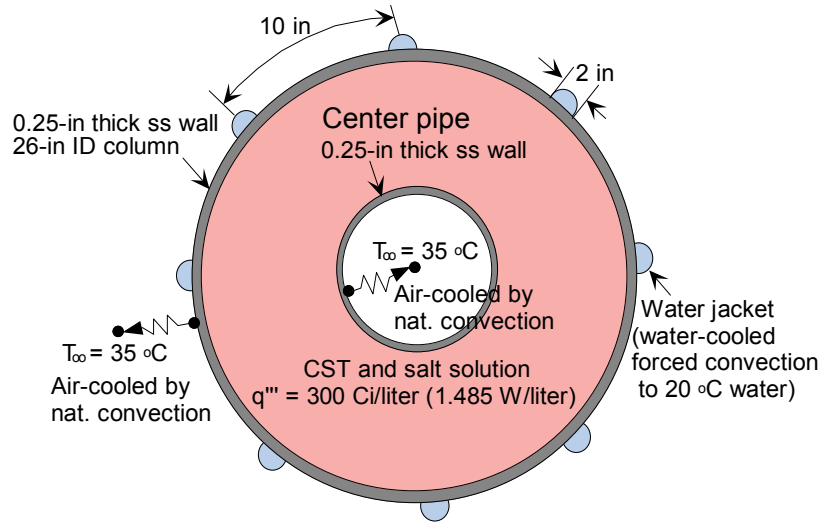

(300 Ci/liter heat load)

\begin{tabular}{|c|c|c|c|c|}
\hline \multirow{2}{*}{ Parameter } & \multicolumn{4}{|c|}{ Center pipe diameter } \\
\cline { 2 - 5 } & 0 in & 2 in & 3 in & 6 in \\
\hline Max. temperature & $168^{\circ} \mathrm{C}$ & $143^{\circ} \mathrm{C}$ & $134^{\circ} \mathrm{C}$ & $114^{\circ} \mathrm{C}$ \\
\hline
\end{tabular}


Table 10. Steady-state maximum temperatures with the $300 \mathrm{Ci} /$ liter column cooled by mixed convection under the Case-III design with the 26 -in ID column volume (ambient temp. $=35^{\circ} \mathrm{C}$ and water jacket temperature $=20^{\circ} \mathrm{C}$ ).

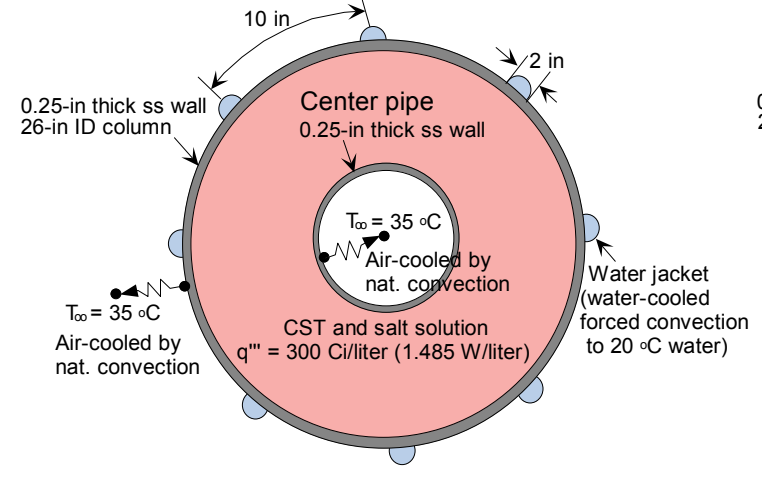

(Case-IIla)

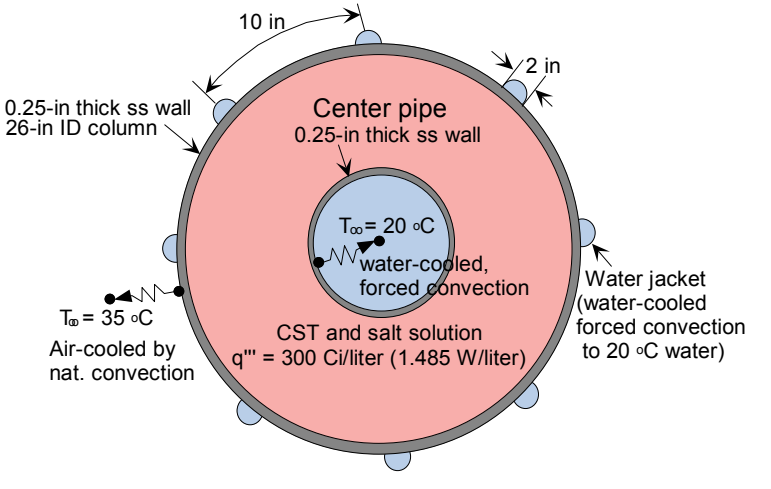

(Case-IIIb)

\begin{tabular}{|c|c|c|}
\hline \multirow{2}{*}{ Parameter } & \multicolumn{2}{|c|}{ 6-in OD pipe imbedded at the center of Case-III column } \\
\cline { 2 - 3 } & Air-filled empty pipe (Case-IIla) & Water-filled pipe (Case-IIIb) \\
\hline Max. temperature & $114^{\circ} \mathrm{C}$ & $71^{\circ} \mathrm{C}$ \\
\hline
\end{tabular}

Figure 25 shows the temperature contour plot for the 28 -in column cooled by free and forced convective cooling mechanisms through the inner and outer cooling surfaces when the column is loaded with $300 \mathrm{Ci} /$ liter decay heat as shown in Fig. 4. The figure shows that when ambient air temperature is $35^{\circ} \mathrm{C}$ and water coolant is kept $20{ }^{\circ} \mathrm{C}$, the peak temperature reaches about $71^{\circ} \mathrm{C}$ during no process flow, which is well below the boiling temperature in case of the $300 \mathrm{Ci} /$ liter column.

When the 28-in column with 6-in water coolant pipe penetrated through the column center is cooled by natural convection without water jacket system at the wall surface, peak temperature of the column reaches about $133^{\circ} \mathrm{C}$ as shown in Fig. 26. This is based on the $35^{\circ} \mathrm{C}$ ambient temperature and $20{ }^{\circ} \mathrm{C}$ water coolant of the 6 -in pipe. The 6 -in pipe has a $16 \mathrm{gpm}$ water flowrate.

Four different operating scenarios were simulated under steady-state conditions using the final reference geometry of the 28 -in column as shown in Fig. 4 when the column is loaded with $300 \mathrm{Ci} /$ iter decay heat corresponding to the thermal source of $1.485 \mathrm{~W} / \mathrm{liter}$. The simulation results are shown in Fig. 27 . It is noted that the naturally-cooled 28-in column exceeds the boiling temperature under the heat load condition of $300 \mathrm{Ci} /$ liter. Figure 28 compares peak column temperatures between 4 and 8 water jackets under the same column and heat load. It is shown that the peak temperature of the column with 4 water jackets is about $11{ }^{\circ} \mathrm{C}$ higher than the one with 8 jackets. Steady state maximum temperatures are compared between the two design conditions of 4 and 8 water jackets as function of heat load in Fig. 29. Table 11 shows sensitivity results of the CST temperature responses to the number of water jackets and different coolant temperatures. It is noted that with this design (6 in imbedded pipe and either 4 or 8 
outer jackets), an increase in temperature of the cooling water directly increases the maximum temperature of the column. If chilled $\left(20^{\circ} \mathrm{C}\right)$ water is not available, ambient $\left(30^{\circ} \mathrm{C}\right)$ water prevents the column from boiling.

Table 11. Steady-state maximum temperatures with the $300 \mathrm{Ci} /$ liter column cooled by mixed convection under the Case-III design of the 28-in OD column defined by Fig. 2 (ambient temp. $=35^{\circ} \mathrm{C}$ and water jacket temperature $\left(\mathrm{T}_{\mathrm{wf}}=20^{\circ} \mathrm{C}\right.$ or 30 $\left.{ }^{\circ} \mathrm{C}\right)$.

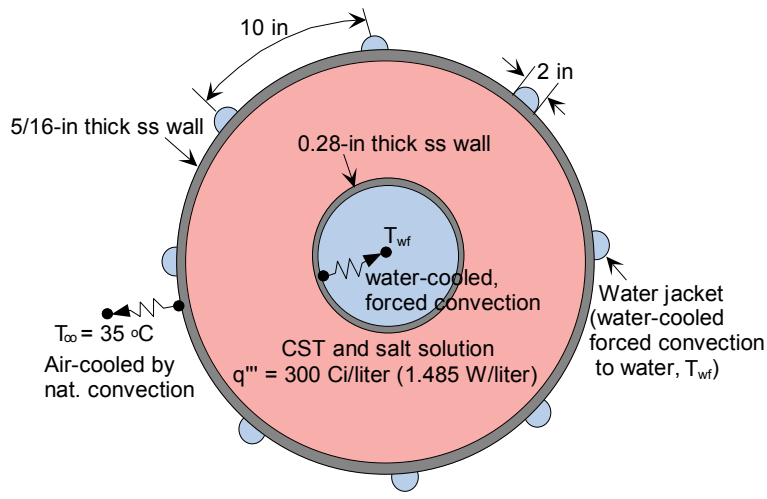

(8 water jackets)

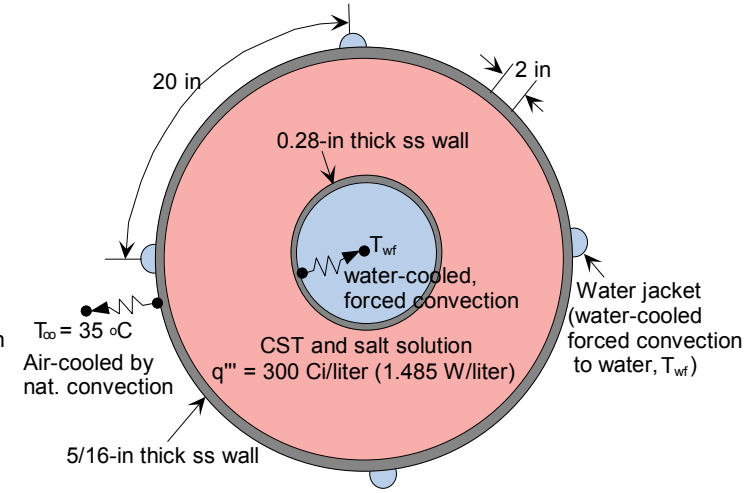

(4 water jackets)

\begin{tabular}{|c|c|c|c|c|}
\hline \multirow{2}{*}{ Parameter } & \multicolumn{2}{|c|}{ 6-in sch. 40 pipe imbedded at center of Case-III column } \\
\cline { 2 - 5 } & \multicolumn{2}{|c|}{8 water jackets } & \multicolumn{2}{c|}{4 water jackets } \\
\hline Water temperature $\left(\mathrm{T}_{\text {wf }}\right)$ & $20^{\circ} \mathrm{C}$ water & $30{ }^{\circ} \mathrm{C}$ water & $20{ }^{\circ} \mathrm{C}$ water & $30{ }^{\circ} \mathrm{C}$ water \\
\hline Max. temperature & $71.1^{\circ} \mathrm{C}$ & $80.8^{\circ} \mathrm{C}$ & $82.1^{\circ} \mathrm{C}$ & $90.9^{\circ} \mathrm{C}$ \\
\hline Min. temperature & $20.14^{\circ} \mathrm{C}$ & $30.1^{\circ} \mathrm{C}$ & $20.2^{\circ} \mathrm{C}$ & $30.2^{\circ} \mathrm{C}$ \\
\hline
\end{tabular}

The peak temperatures for the columns cooled by mixed convection and natural convection mechanisms during no flow conditions are compared in Fig. 30. It makes a large difference in terms of the coolability of the CST column when the water coolant is used in 6-in sch. 40 pipe at the center of the 28-in column. As shown in Fig. 31, the transient results for the column cooled by mixed convection show that it takes about 10 days for the system loaded with $300 \mathrm{Ci} /$ liter decay heat to reach quasi-steady maximum temperature, which is close to boiling temperature.

As one of the operational scenarios, the water jacket system at the external boundary of the column and the 6-in water coolant pipe imbedded at the column center are automatically activated via the engineered emergency cooling system when the maximum temperature of the 28-in CST column reaches $100{ }^{\circ} \mathrm{C}$, close to the boiling temperature, during a no process flow accident. Transient results for the $300 \mathrm{Ci} /$ liter loaded column are shown in Fig. 32. It is noted that the emergency cooling system is 
activated about 56 hours after the initiation of the no process flow situation and the temperature trend reverses from increasing to decreasing about 12 hours after the activation of the emergency water cooling system. The transient heat response of a conduction medium containing a heat source to the environment with lower temperature is closely related to its thermal diffusivity. The thermal diffusivity $\alpha$ is defined as the ratio of thermal conductivity to the product of density and specific heat. The CST column medium during no flow situation has a small value of $\alpha$, that is, about $7.66 \times 10^{-4}$ $\mathrm{cm}^{2} / \mathrm{sec}$. This parameter is a measure of temperature-wave penetration depth for a given time. As shown in Fig. 17, the CST-salt column with no process flow heats up slower because of higher thermal mass and lower thermal conductivity.

The parameters studied in the previous work [4] were based on back-filled material of the CST column, porosity of the packed column, and cooling mechanism of the CST column with no process flow situation. The present work was focussed on the studies on the column geometry and the cooling mechanisms equipped with engineered cooling system since the 28-in column with $300 \mathrm{Ci} /$ liter heat load potentially exceeds boiling temperature under the passive natural convection system in case of no process flow situations, which is one of the undesirable operating conditions.

Sensitivity runs of different convection cooling mechanisms such as natural convection and mixed natural and forced convection have been performed by the same heat transfer model (shown in Fig. 4) with the same thermal and material properties but different heat transfer coefficients at the boundary of the CST fixed bed. In this case, the analysis of this parameter was made only for the CST-salt column during no flow process situation as expected. Four different cases for the final 28-in CST column with 6-in coolant pipe at its center were studied to estimate how effectively the cooling mechanisms affect the coolability and temperature profile of the column. The first two cases (case-a and Case-a1) were for mixed convection cooling conditions including the water jacket system and 6-in water-cooled pipe, the third one (Case-b) was for the mixed convection cooled only by the water-cooled pipe at the column center, and the fourth one (Case-c) was for the passive cooling system controlled only by natural convection. The results indicated that cooling mechanism at the wall has significant impact on the wall surface temperature and radial temperature gradient of the column, and cooling mechanism at the center has significant impact on the peak temperature of the column resulting the location change of the column peak temperature. The temperature results of the four cases are presented in Fig. 27.

From the sensitivity study of the CST column design parameters, it was found that 6-in water-coolant pipe penetrated through the center of the packed CST bed effectively controlled the temperature distributions of the column associated with the heatup rate of the $300 \mathrm{Ci} /$ liter CST column under loss-of-flow conditions. Table 10 shows summary of the sensitivity analysis results. 


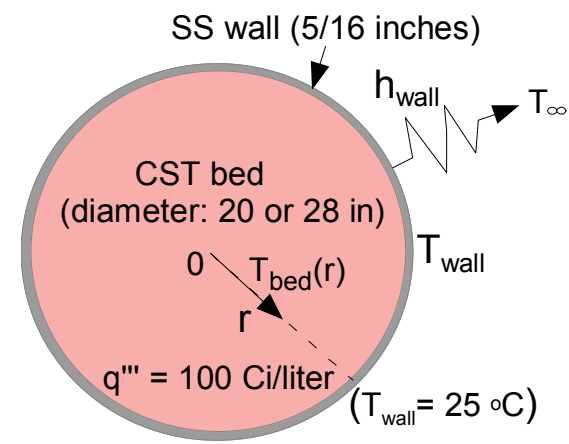

(Case-I type column)

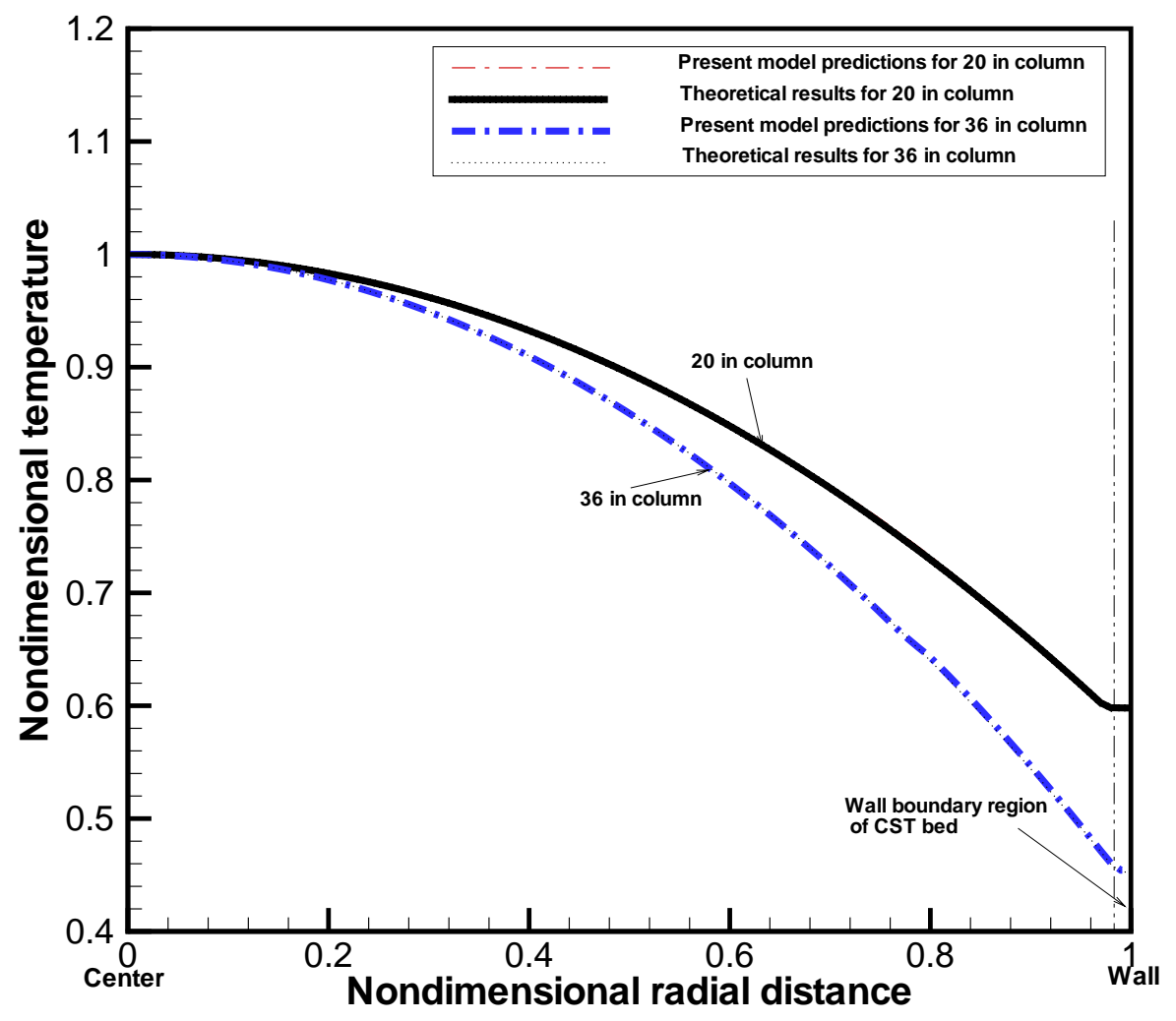

$$
\begin{gathered}
\text { (nondimensional radial distance } \eta=\frac{r}{R+d}, \\
\text { nondimensional temperature } \left.\theta_{00}=\frac{T(t \rightarrow \infty, r)-T_{\infty}}{T(t \rightarrow \infty, r=0)-T_{\infty}}\right)
\end{gathered}
$$

Figure 10. Comparison of steady state results between the numerical computations and theoretical results for the Case-I type column under the reference conditions as defined in Table 4 (100 Ci/liter). 


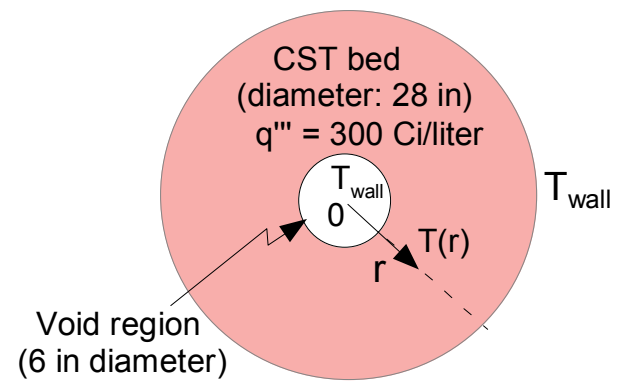

(Case-III type column)

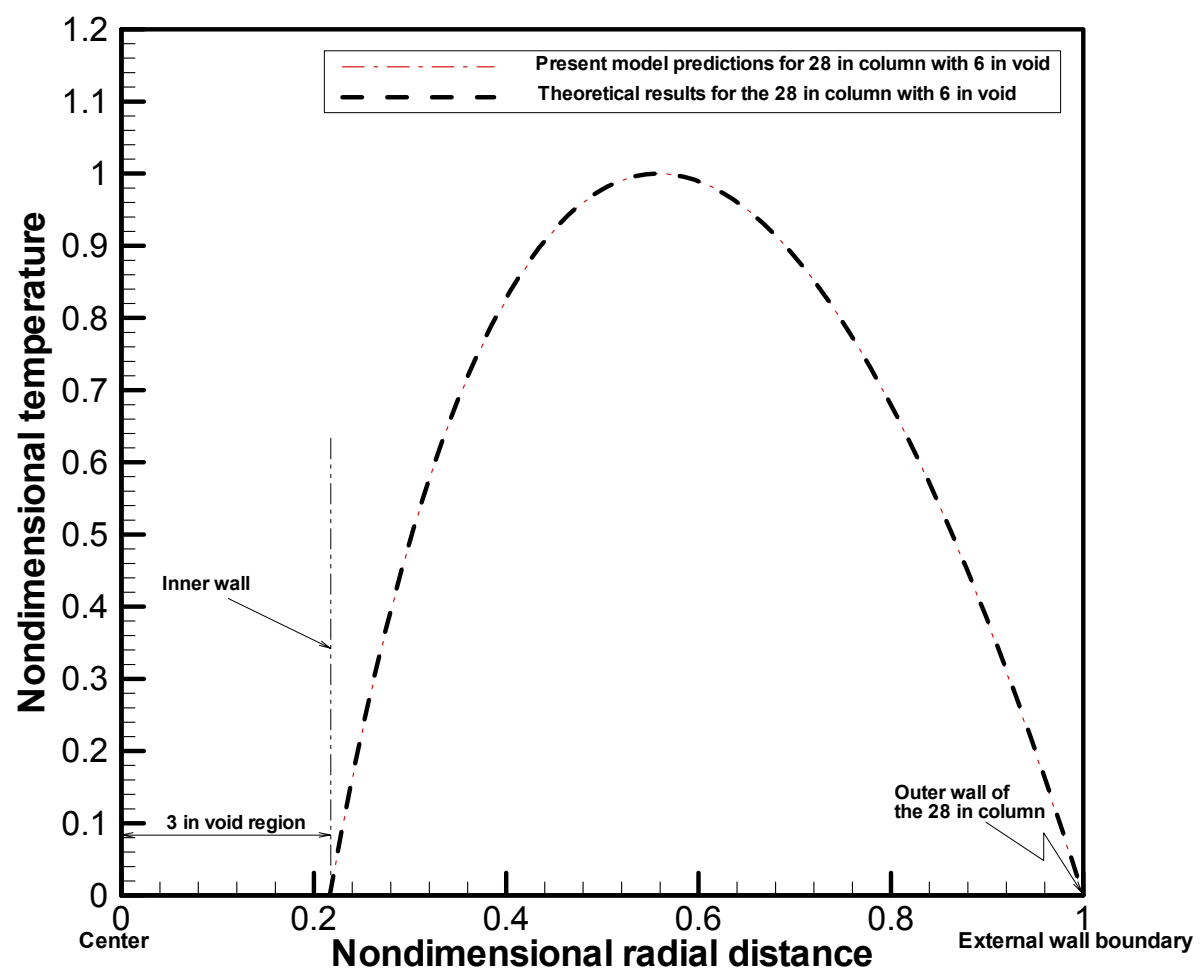

(nondimensional radial distance $\eta=\frac{r}{R+d}$, nondimensional temperature $\left.\theta_{0 w}=\frac{T(t \rightarrow \infty, r)-T_{\text {wall }}}{T\left(t \rightarrow \infty, r=r_{\text {max }}\right)-T_{\text {wall }}}\right)$

Figure 10a. Comparison of steady state results between the numerical computations and theoretical results for the Case-III type column under the reference conditions as defined in Table 4 (300 Ci/liter). 


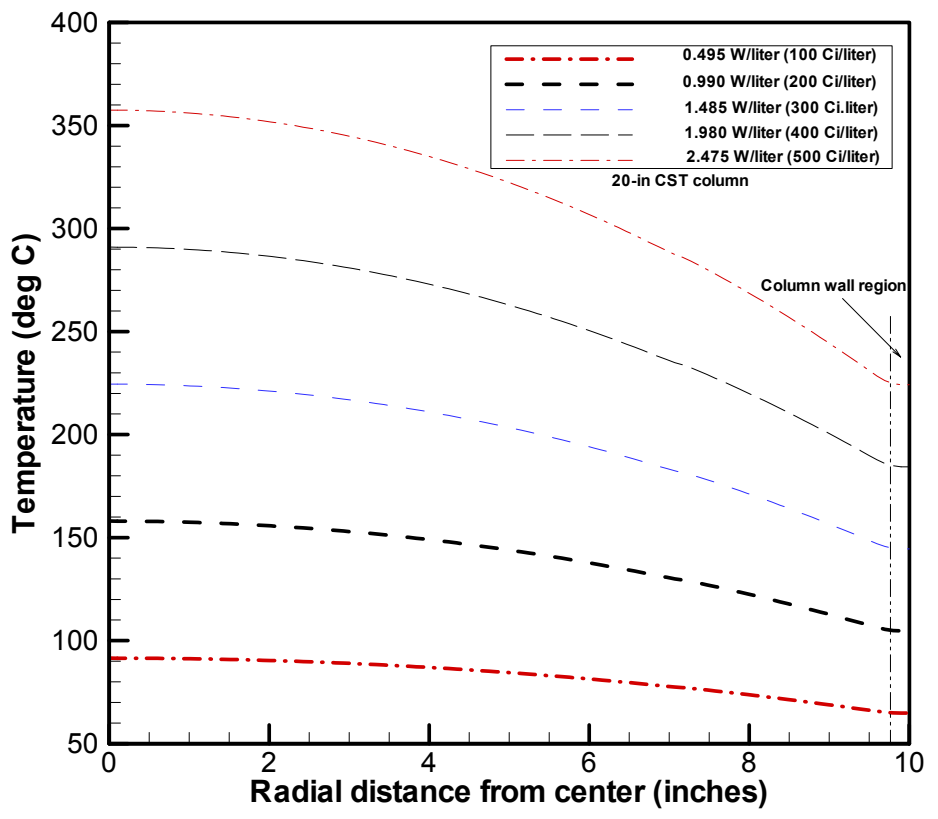

Figure 11. Comparison of steady state results for various heat sources of the CST-salt solution under the reference conditions (20 in column) as defined in Table 1.

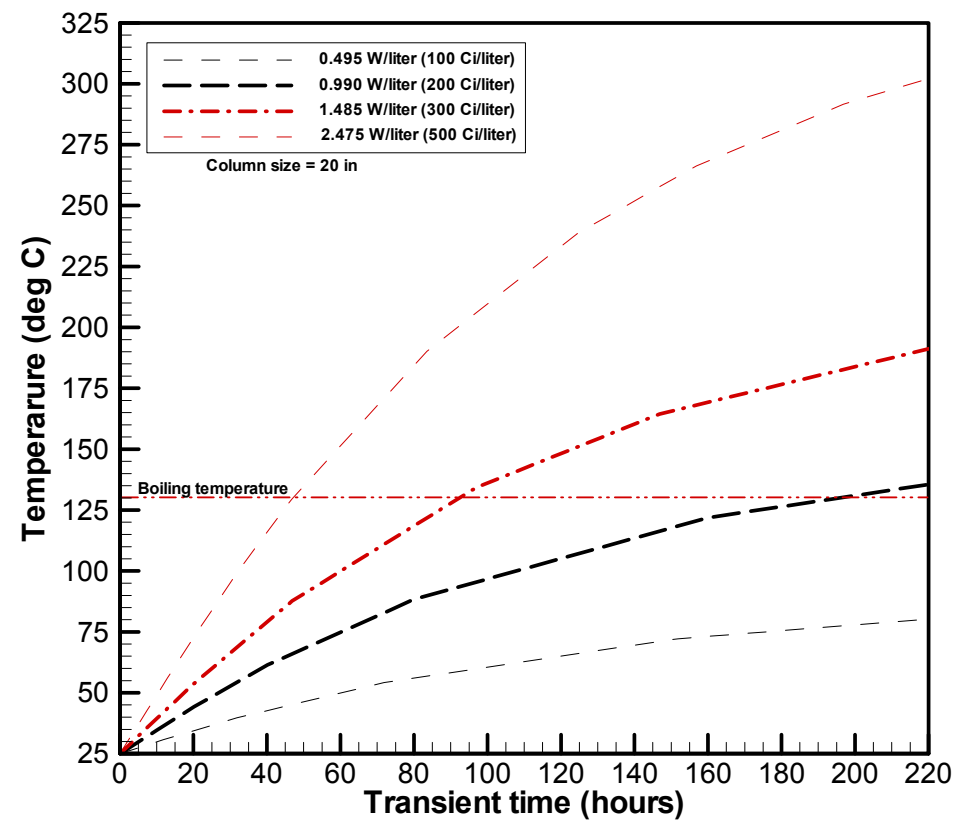

Figure 12. Transient temperature responses of CST column for 20 in column with different heat load under the reference conditions as defined in Table 1. 

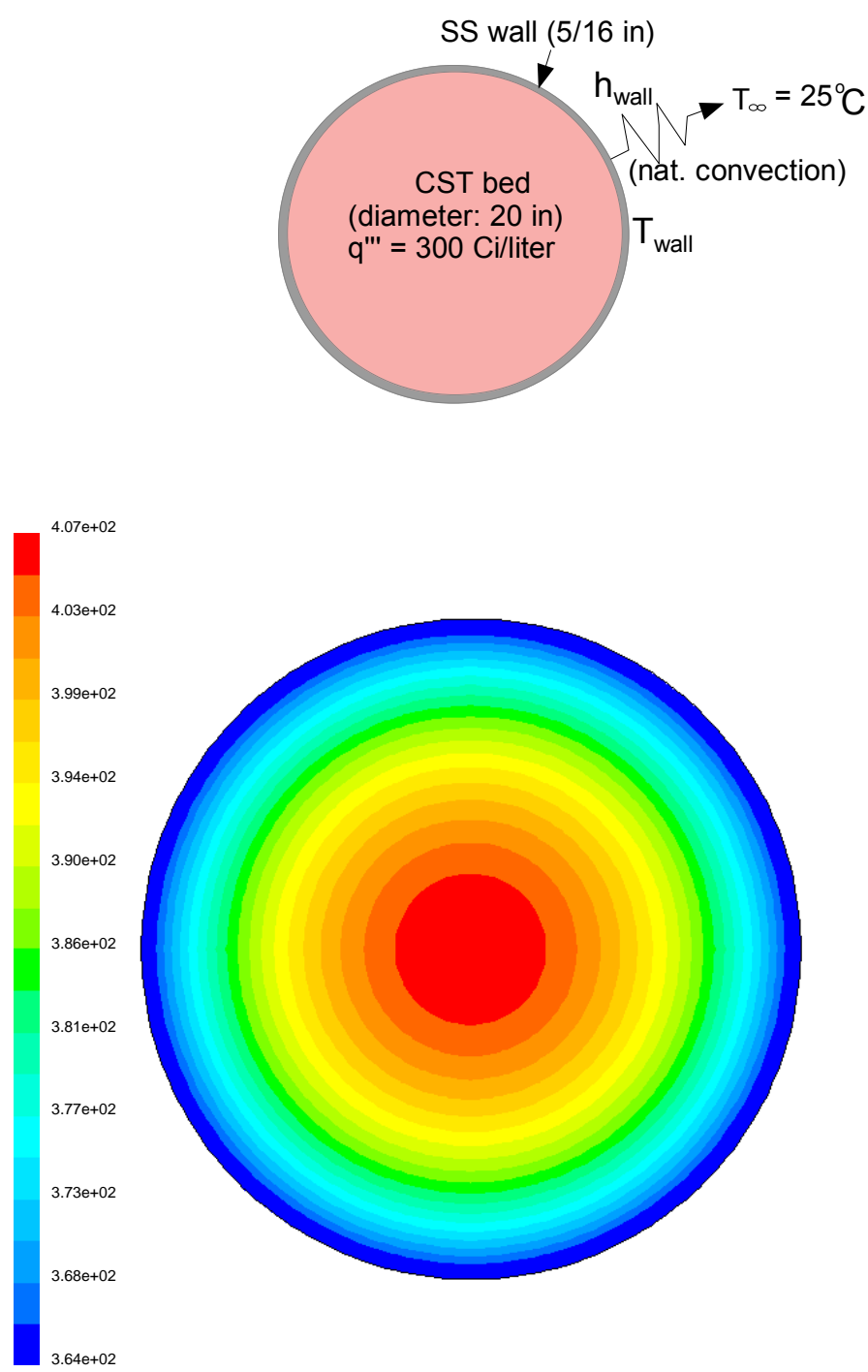

Figure 13. Temperature contour plot for naturally-cooled CST-salt solution bed column with $300 \mathrm{Ci} /$ liter and $25^{\circ} \mathrm{C}$ ambient and initial temperatures at the transient time of 96 hours just as maximum temperature exceeds the boiling temperature (20-in column). 


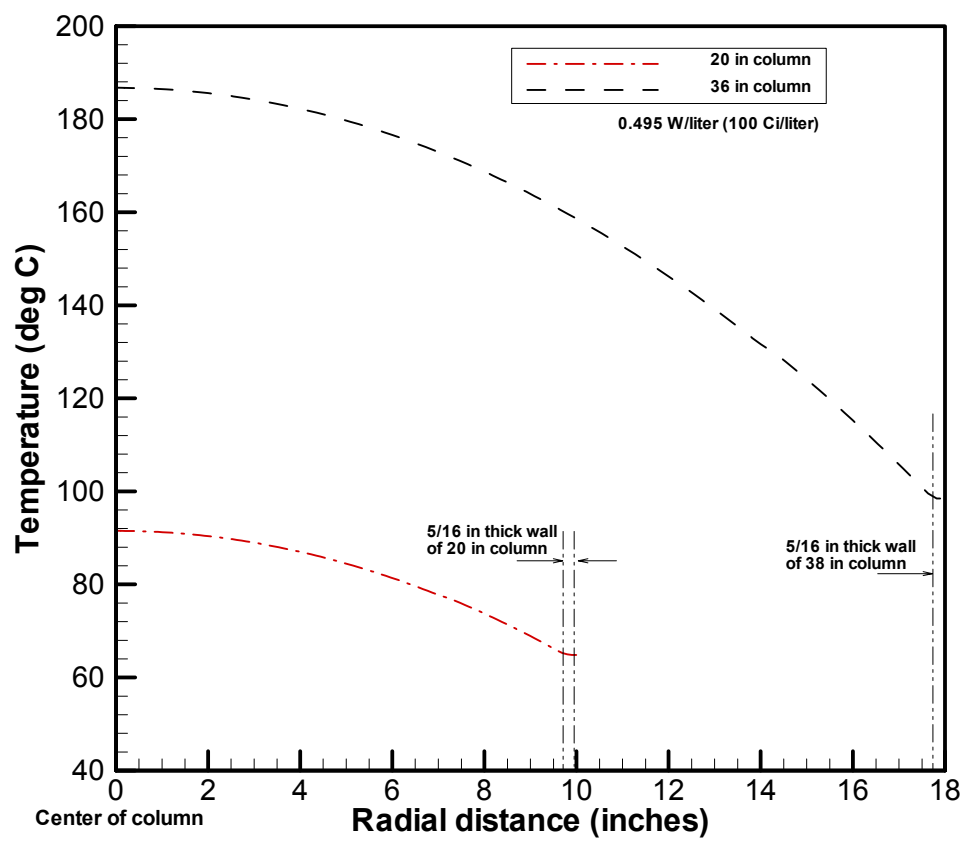

Figure 14. Comparison of steady state results for two different sizes of the CST columns under the reference conditions as defined in Table 4.

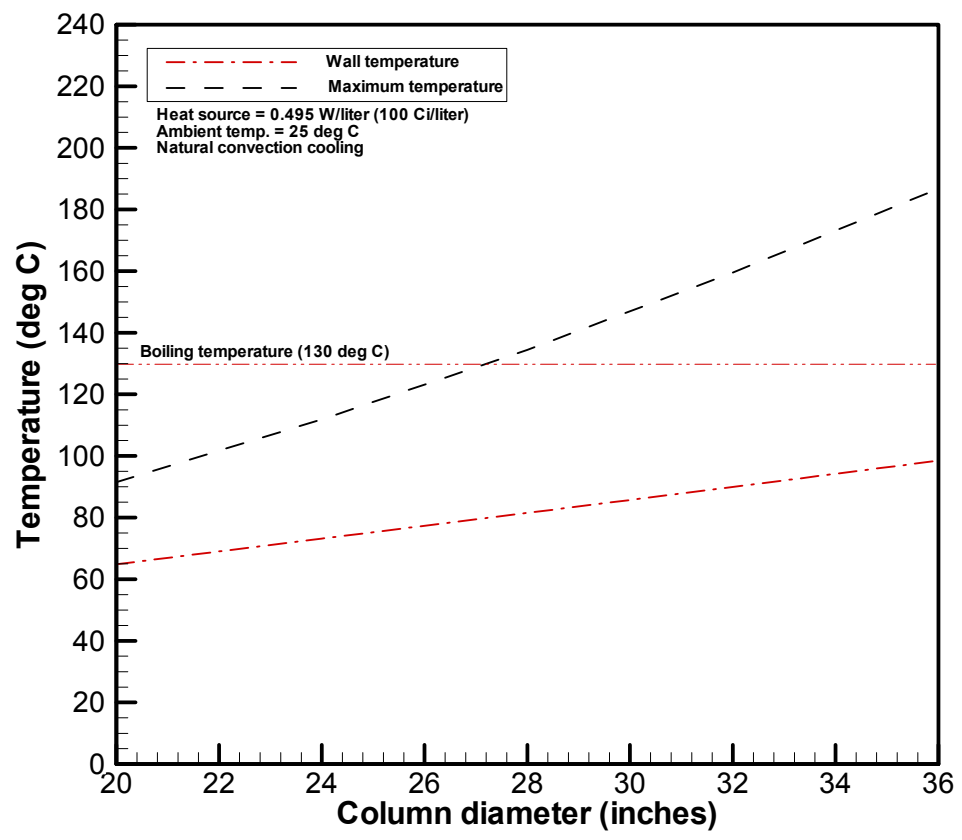

Figure 15. Comparison of steady state results for various sizes of the CST columns under the reference conditions as defined in Table 4. 


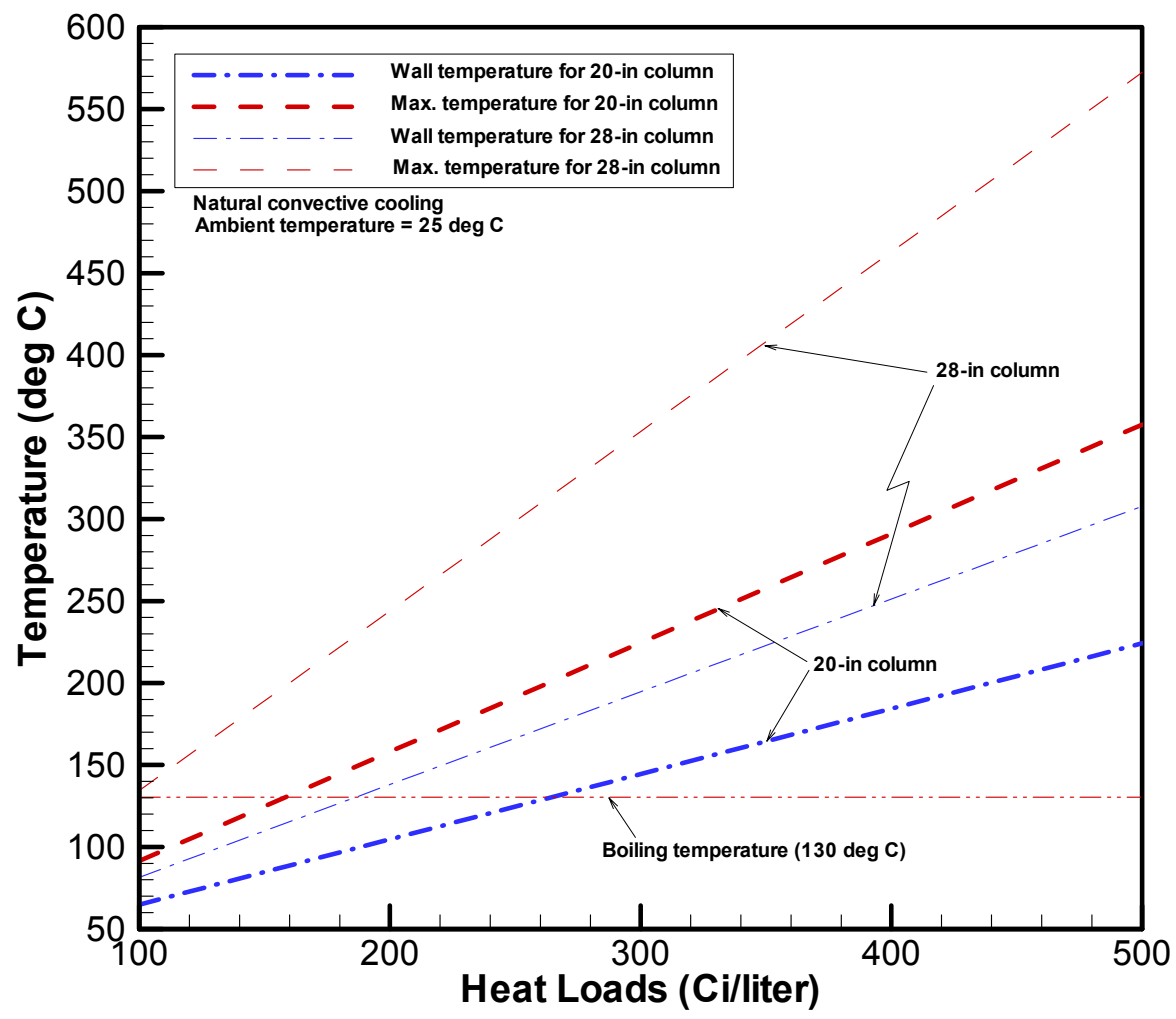

Figure 16. Maximum and wall temperatures of CST column as function of heat loads for 20 in and 28 in columns under the reference conditions as defined in Table 4. 


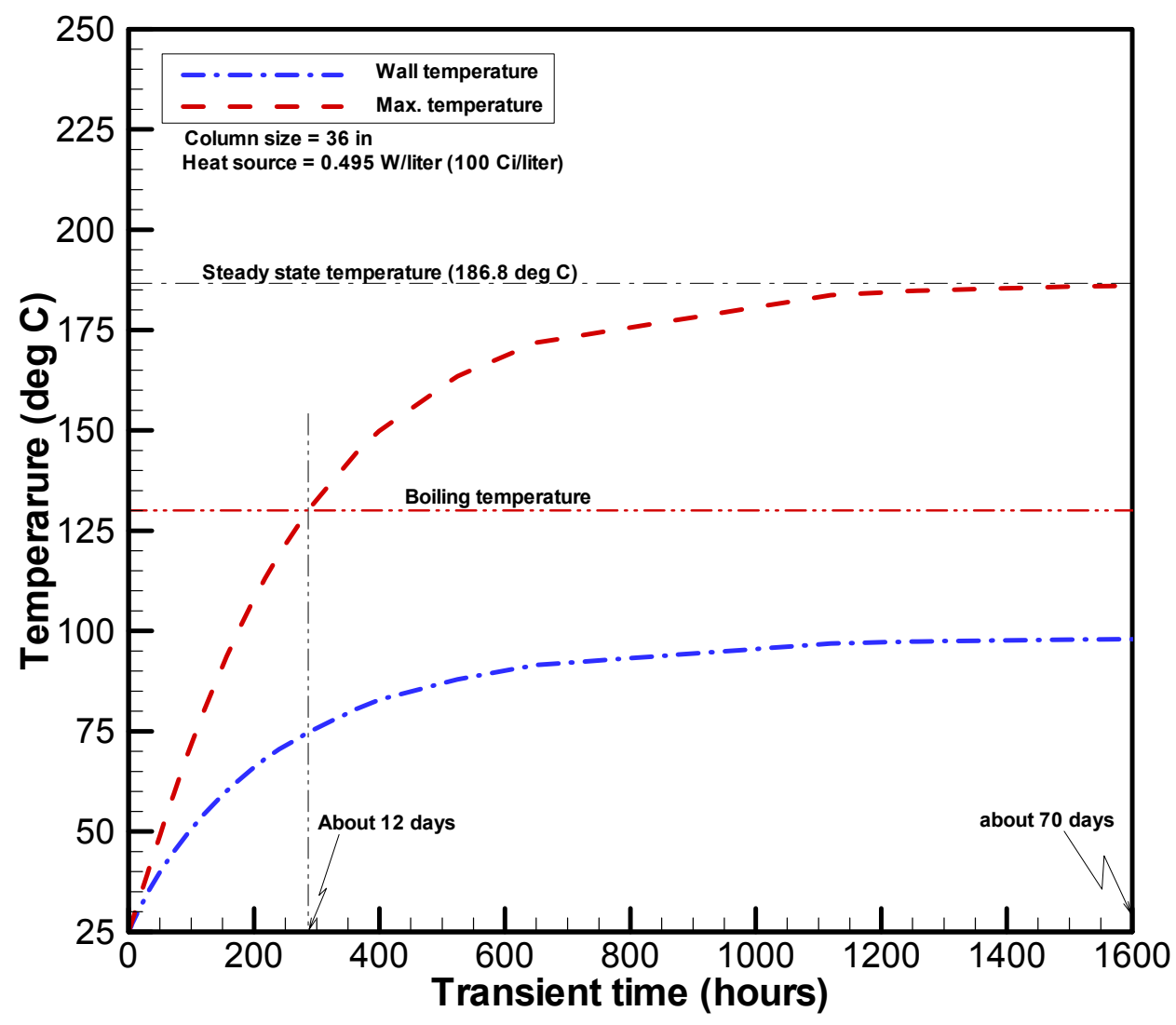

Figure 17. Transient temperature responses of CST column for 36 in column with 100 $\mathrm{Ci} /$ liter heat load under the reference conditions as defined in Table 4. 
Report: WSRC-TR-2003-00416

Date: $\quad 12 / 8 / 2003$

Page: $\quad 36$ of 52
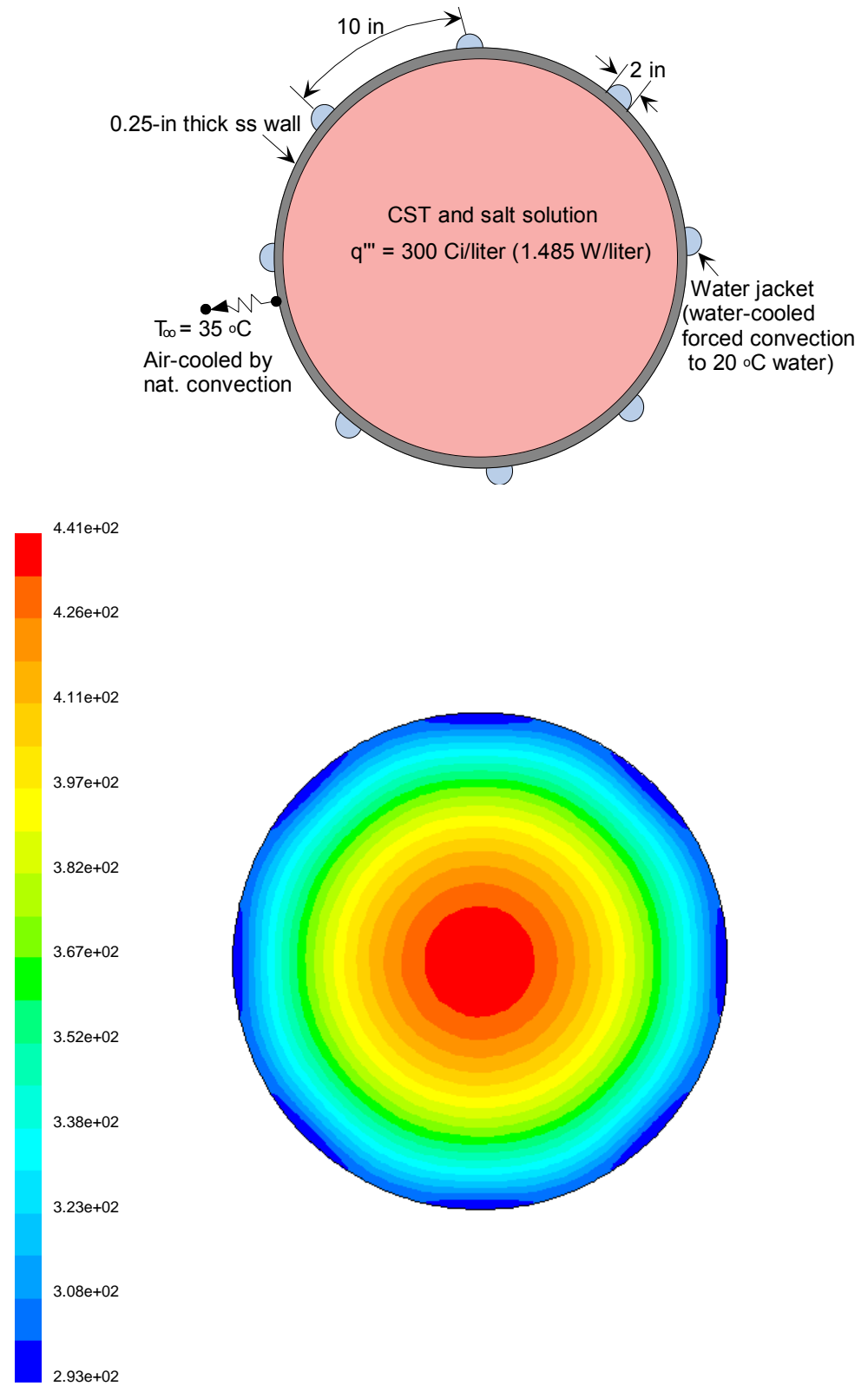

Aug 08, 2003

FLUENT 6.0 (2d, segregated, lam)

Figure 18. Comparison of temperature distributions for 26 -in column with 8 2-in water jackets with $300 \mathrm{Ci} /$ liter heat load 


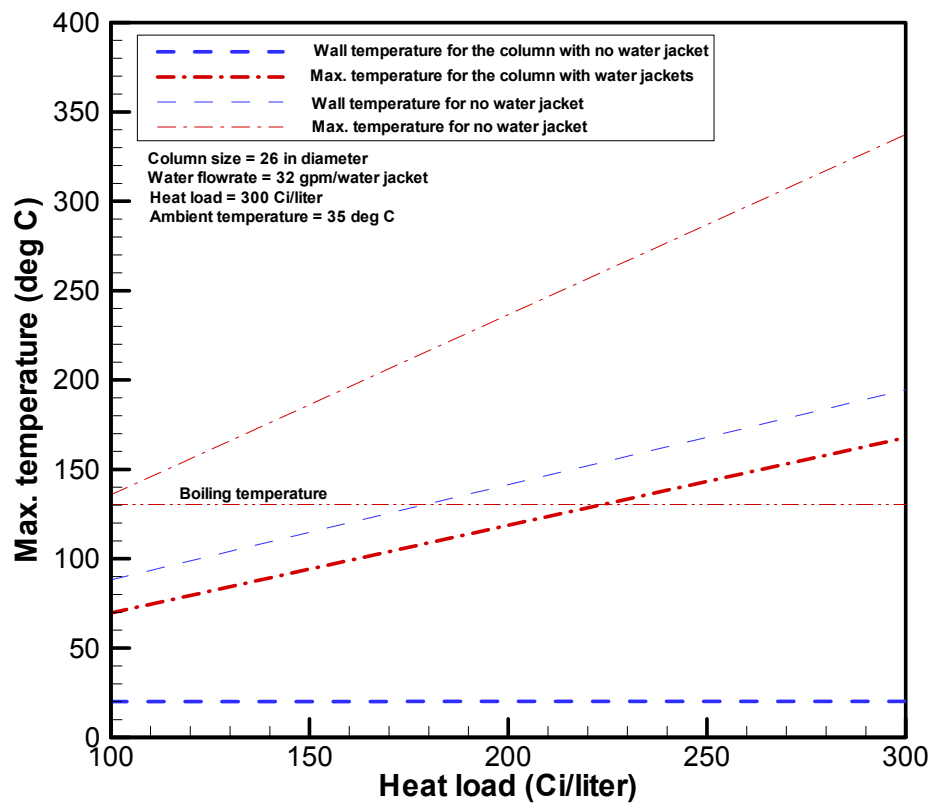

Figure 19. Comparison of temperature distributions for 26 -in column with $300 \mathrm{Ci} /$ liter heat load

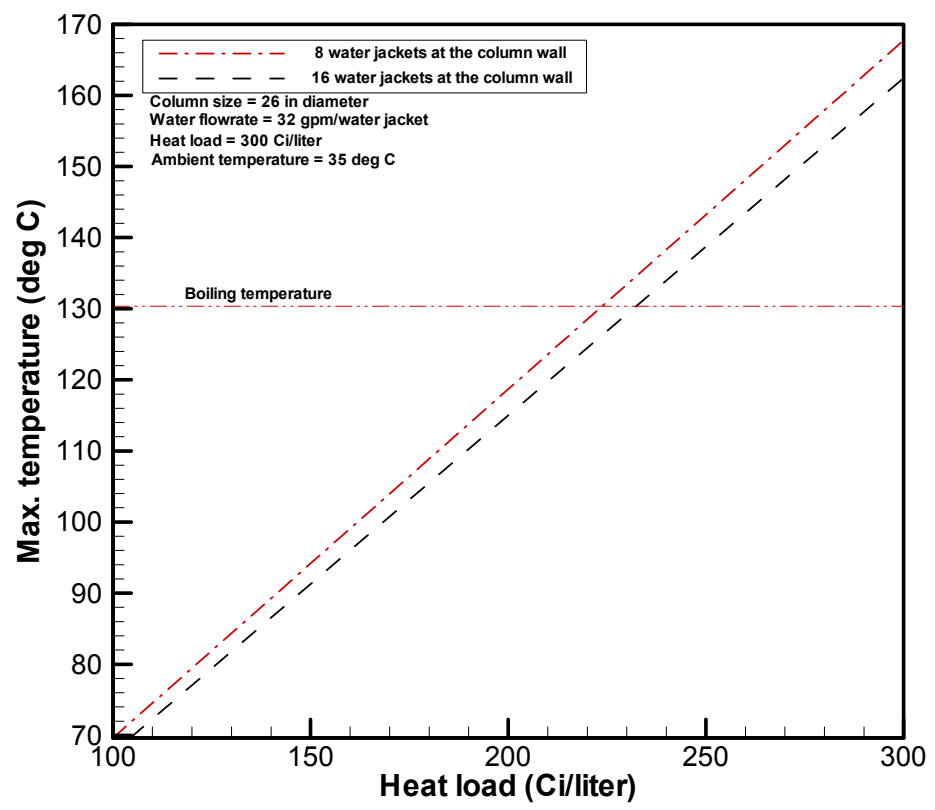

Figure 20. Comparison of temperature distributions for 26 -in column with $300 \mathrm{Ci} /$ liter heat load 


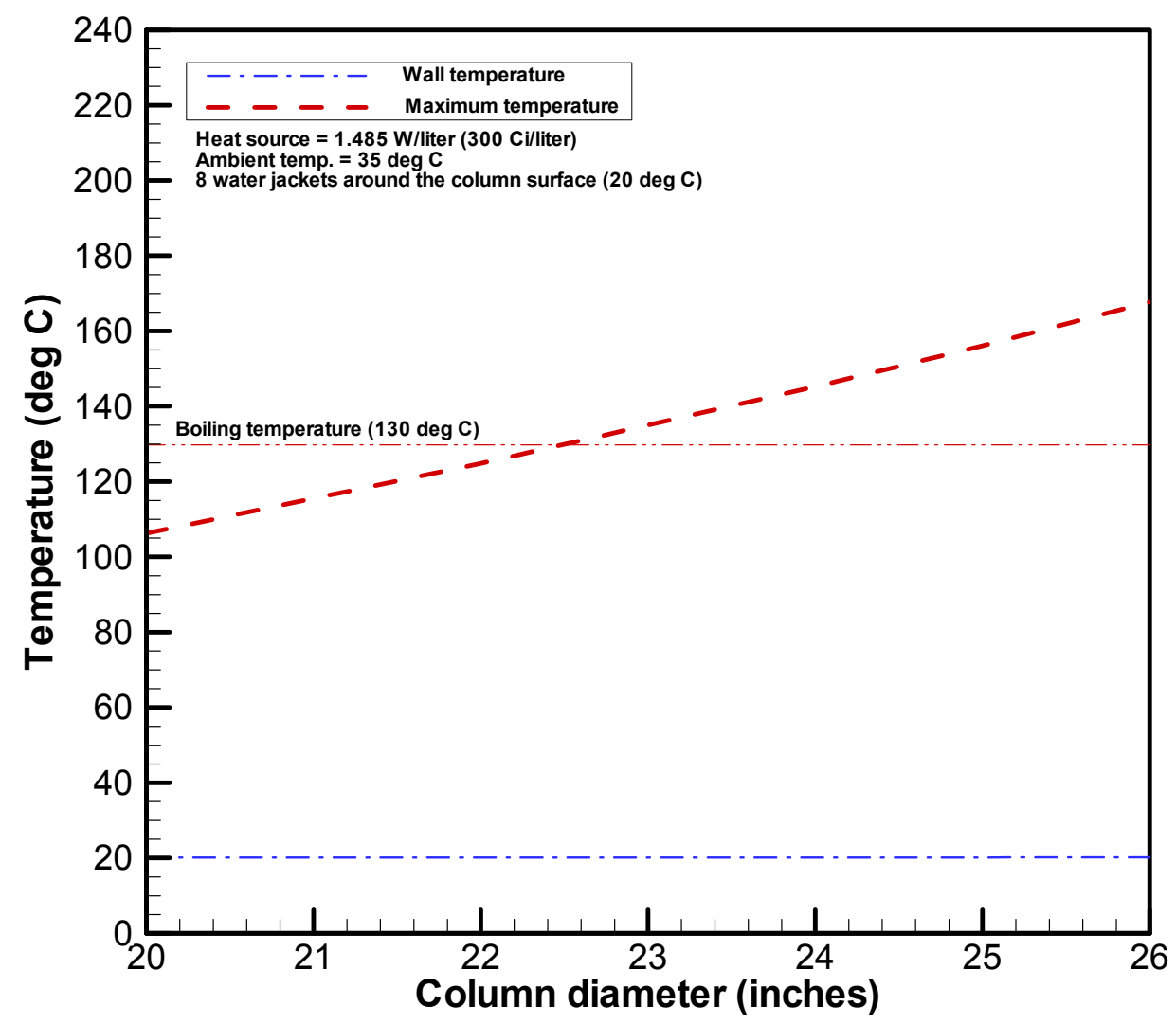

Figure 21. Maximum and wall temperatures as function of column diameter for 300 $\mathrm{Ci} /$ liter heat load 

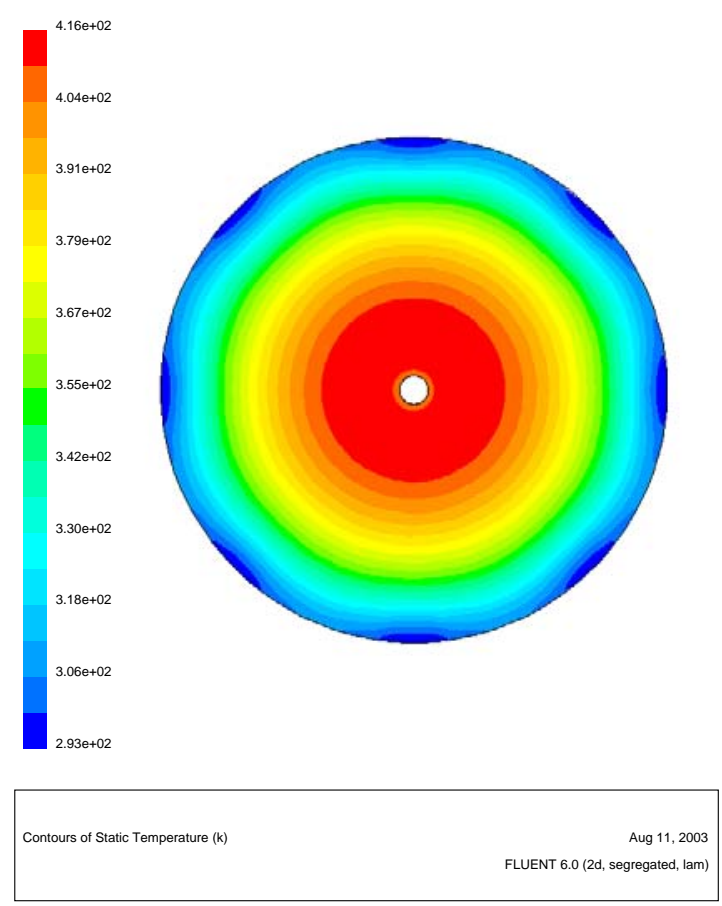

Figure 22. Temperature distributions for the annular column with $300 \mathrm{Ci} /$ liter heat load maintaining the volume of 26 -in cylindrical column (2-in void) $\left(\mathrm{T}_{\max }=143^{\circ} \mathrm{C}\right)$

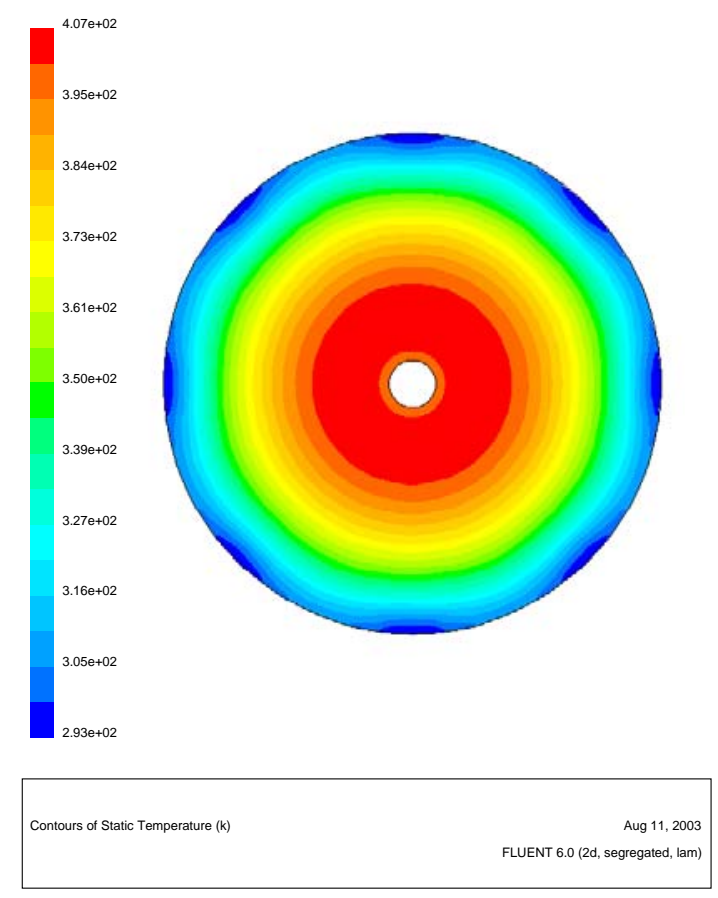

Figure 23. Temperature distributions for the annular column with $300 \mathrm{Ci} /$ liter heat load maintaining the volume of 26-in cylindrical column (3-in void) $\left(T_{\max }=133.5\right.$ $\left.{ }^{\circ} \mathrm{C}\right)$ 

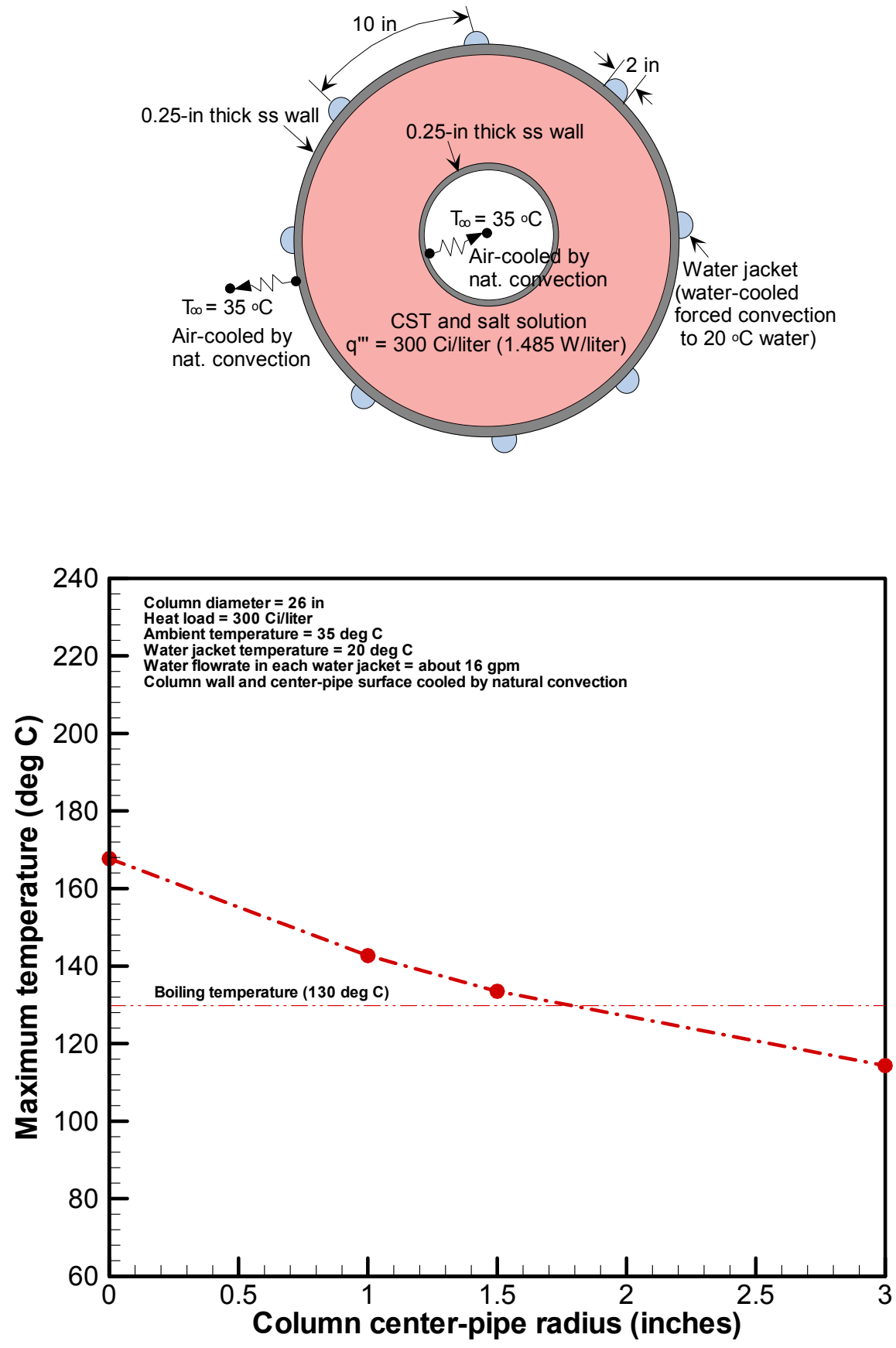

Figure 24. Maximum temperatures for different sizes of center holes of the CST column maintaining the 26 -in ID column volume (300 Ci/liter) 

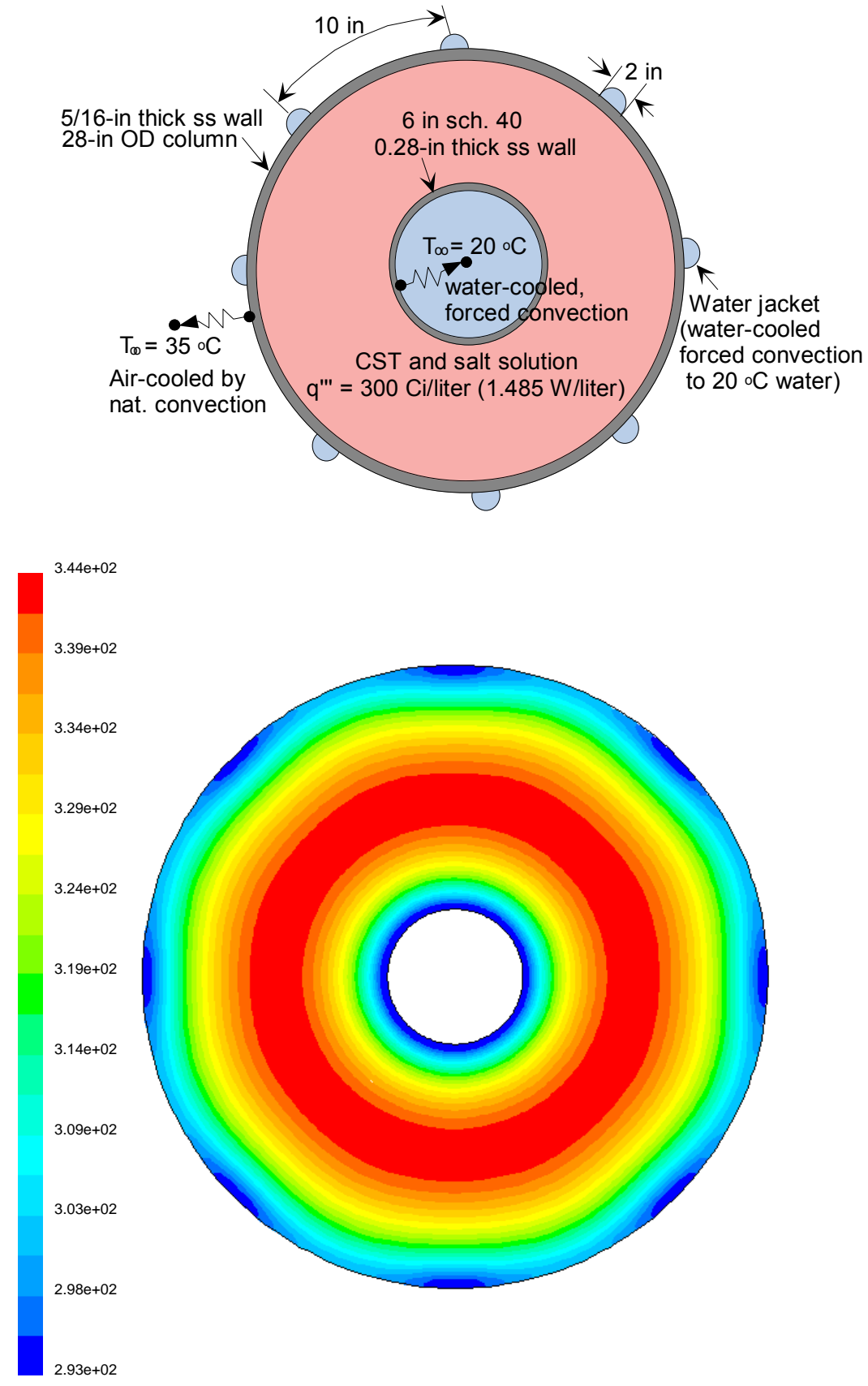

Figure 25. Temperature distributions for the 28-in OD CST column with 6-in watercoolant pipe at its center $(300 \mathrm{Ci} /$ liter heat load $)\left(\mathrm{T}_{\max }=71^{\circ} \mathrm{C}\right)$ 

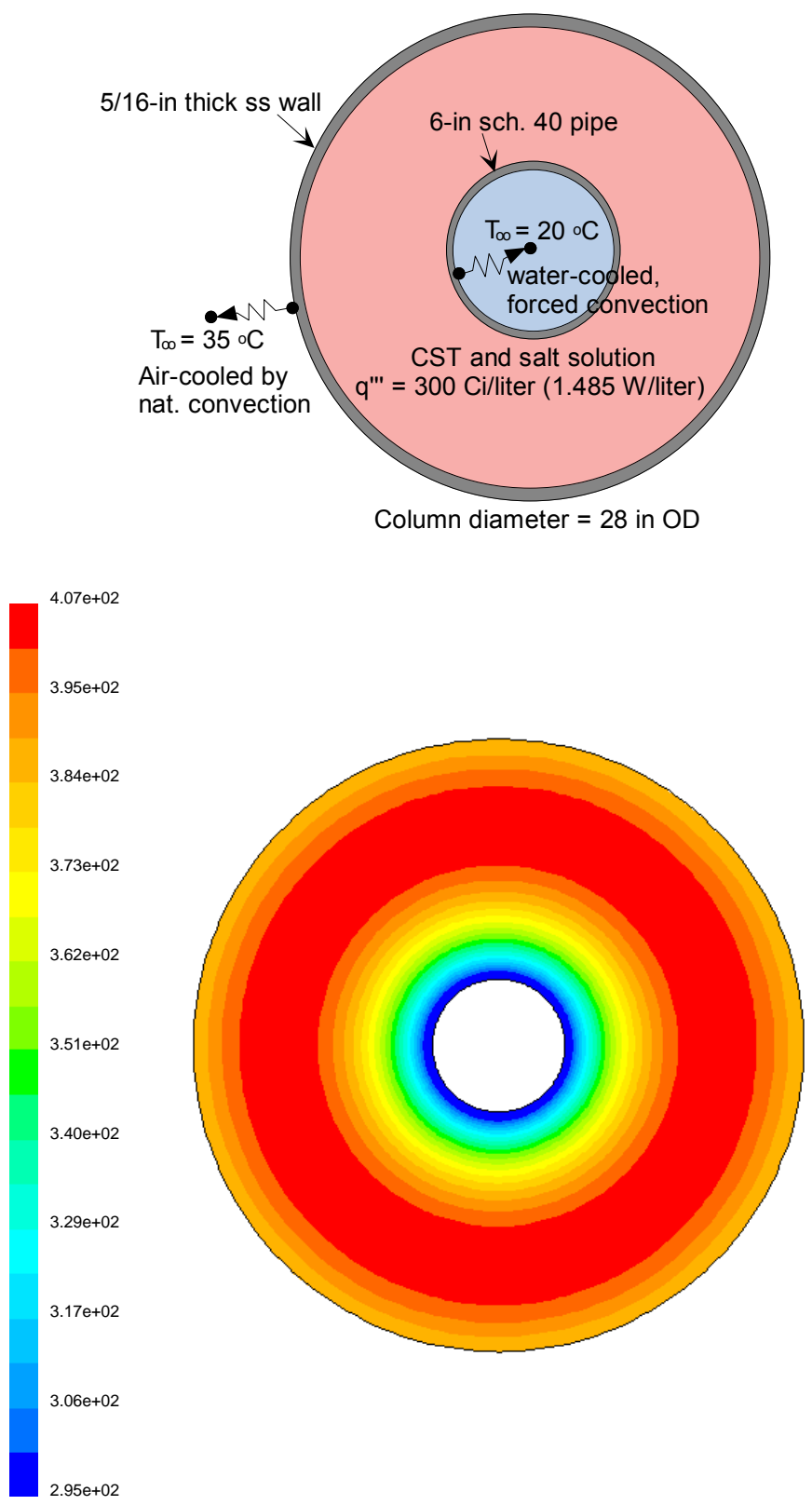

Figure 26. Temperature distributions for the 28-in OD CST column with 6-in sch. 40 water-coolant pipe imbedded at its center and no water jacket on the column wall $(300 \mathrm{Ci} /$ liter heat load $)\left(\mathrm{T}_{\max }=133.4^{\circ} \mathrm{C}\right)$ 


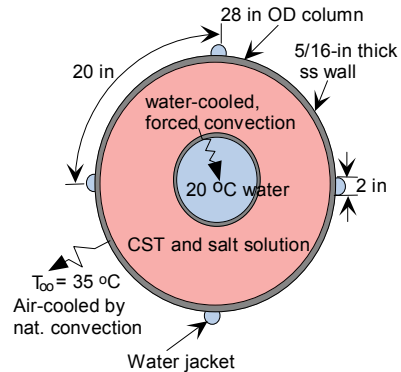

(4 water jackets)

(Case-a)

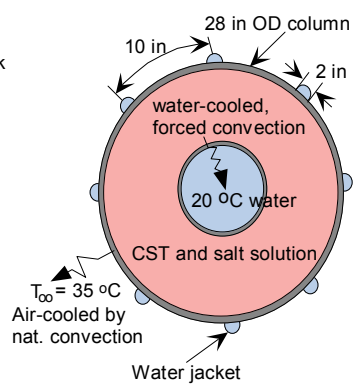

(8 water jackets)

(Case-a1)

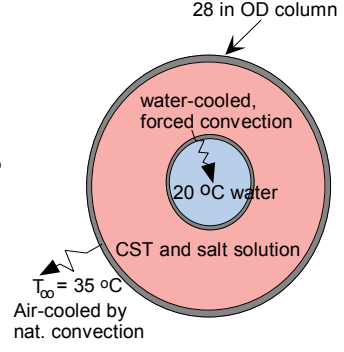

(Case-b)

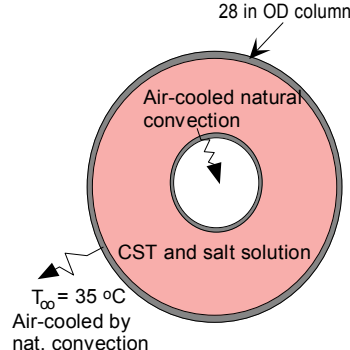

nat. convection

(Case-c)

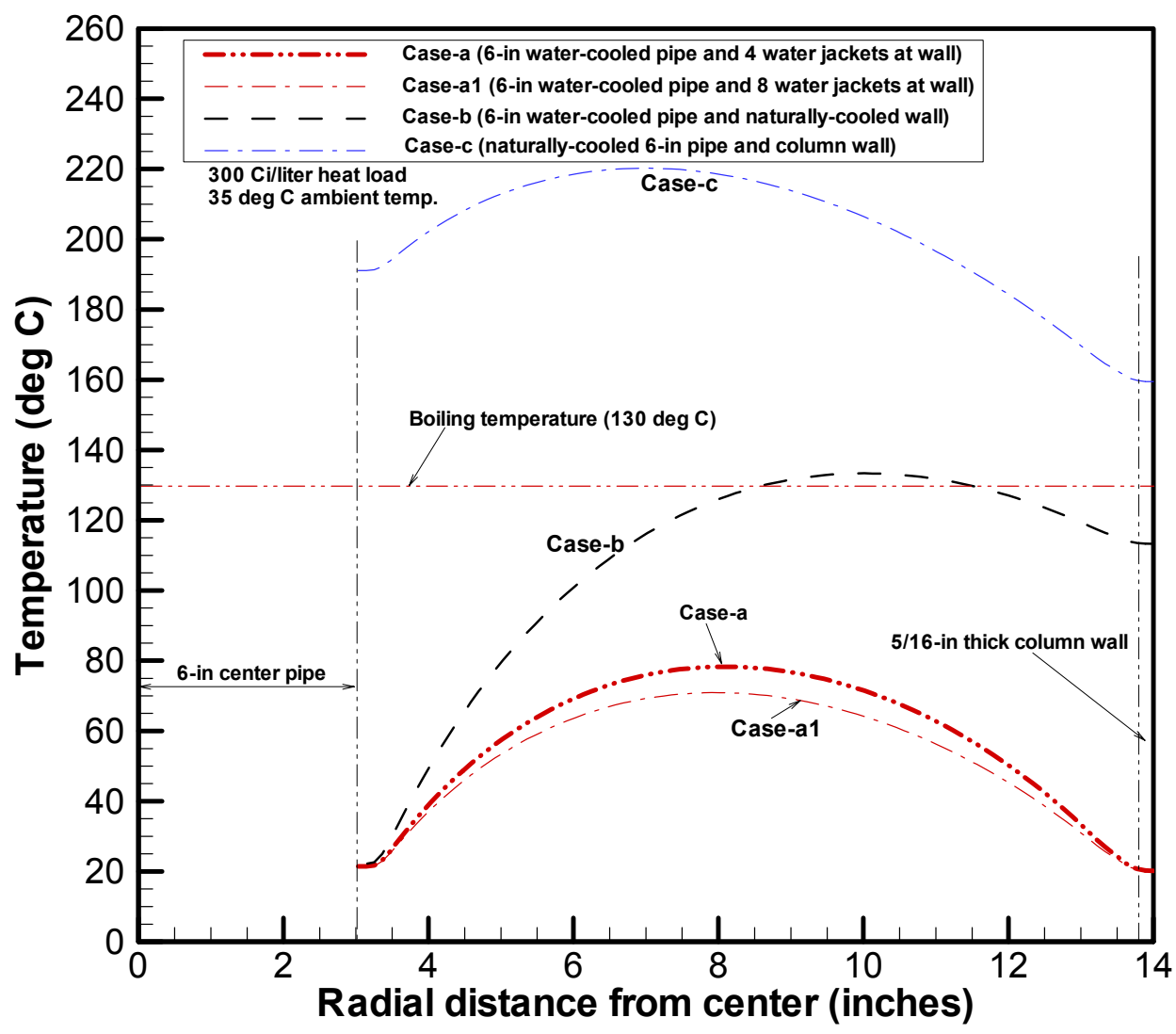

Figure 27. Temperature distributions for various operating cases of the 28-in CST columns of the Case-III and Case-IV designs loaded with $300 \mathrm{Ci} /$ liter volumetric heat source 


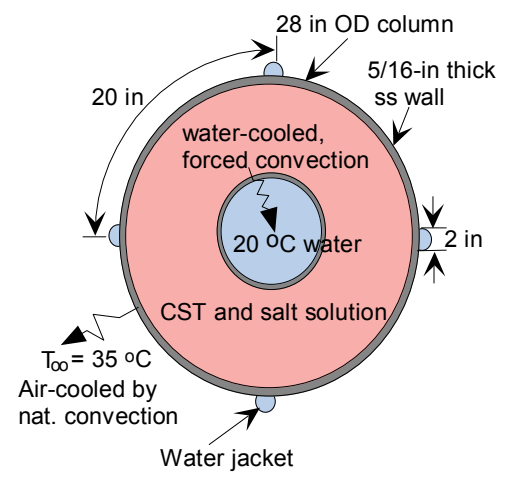

(4 water jackets)

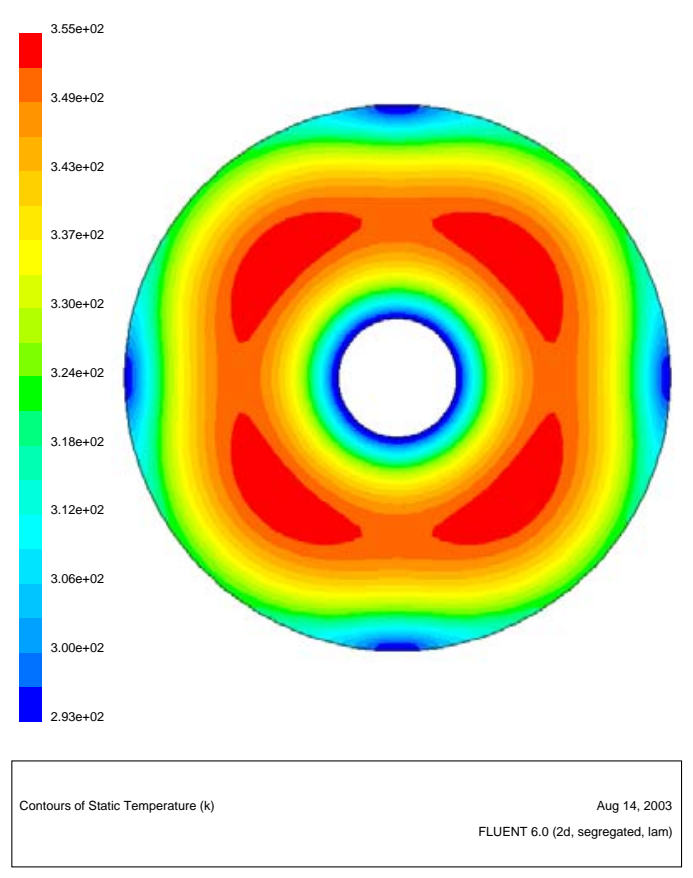

(column with 4 water jackets)

$$
\begin{aligned}
& \mathrm{T}_{\max }=82.1^{\circ} \mathrm{C} \\
& \mathrm{T}_{\text {min }}=20.2^{\circ} \mathrm{C}
\end{aligned}
$$
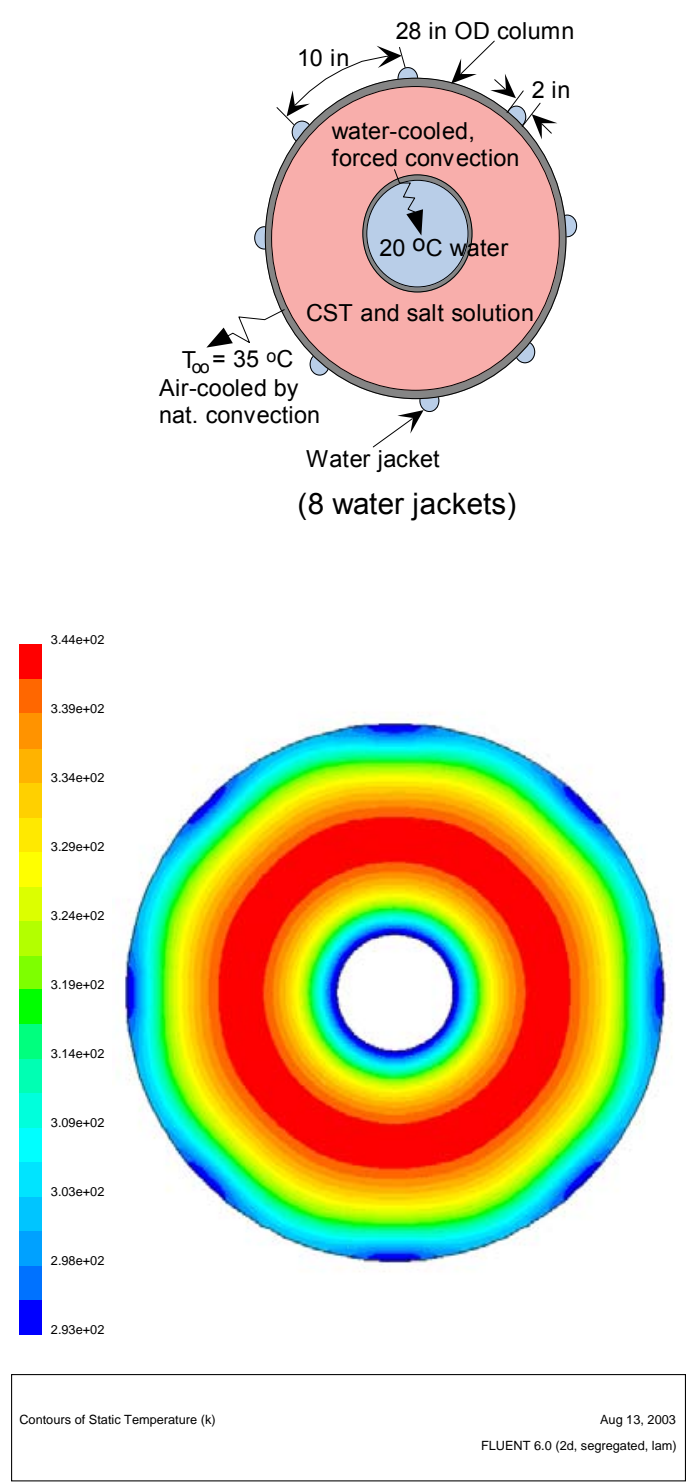

(column with 8 water jackets)

$$
\begin{aligned}
& \mathrm{T}_{\text {max }}=71.1^{\circ} \mathrm{C} \\
& \mathrm{T}_{\text {min }}=20.1^{\circ} \mathrm{C}
\end{aligned}
$$

Figure 28. Comparison of temperature distributions between the 4 and 8 water jacketed 28 -in CST columns imbedded with 6 -in pipe at its center $(300 \mathrm{Ci} /$ liter heat load) 


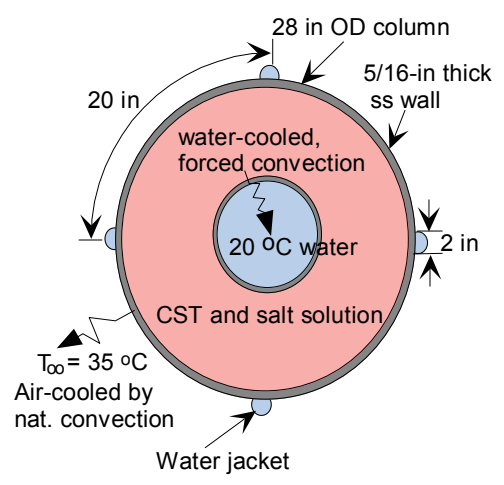

(4 water jackets)

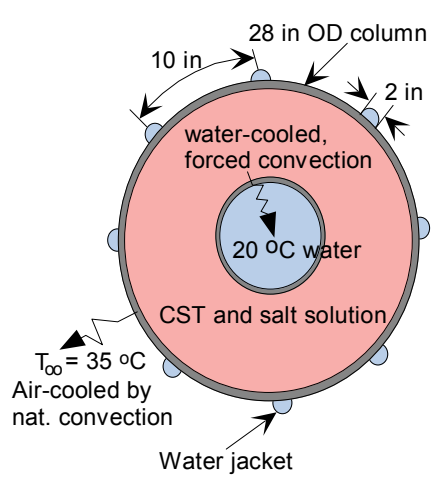

(8 water jackets)

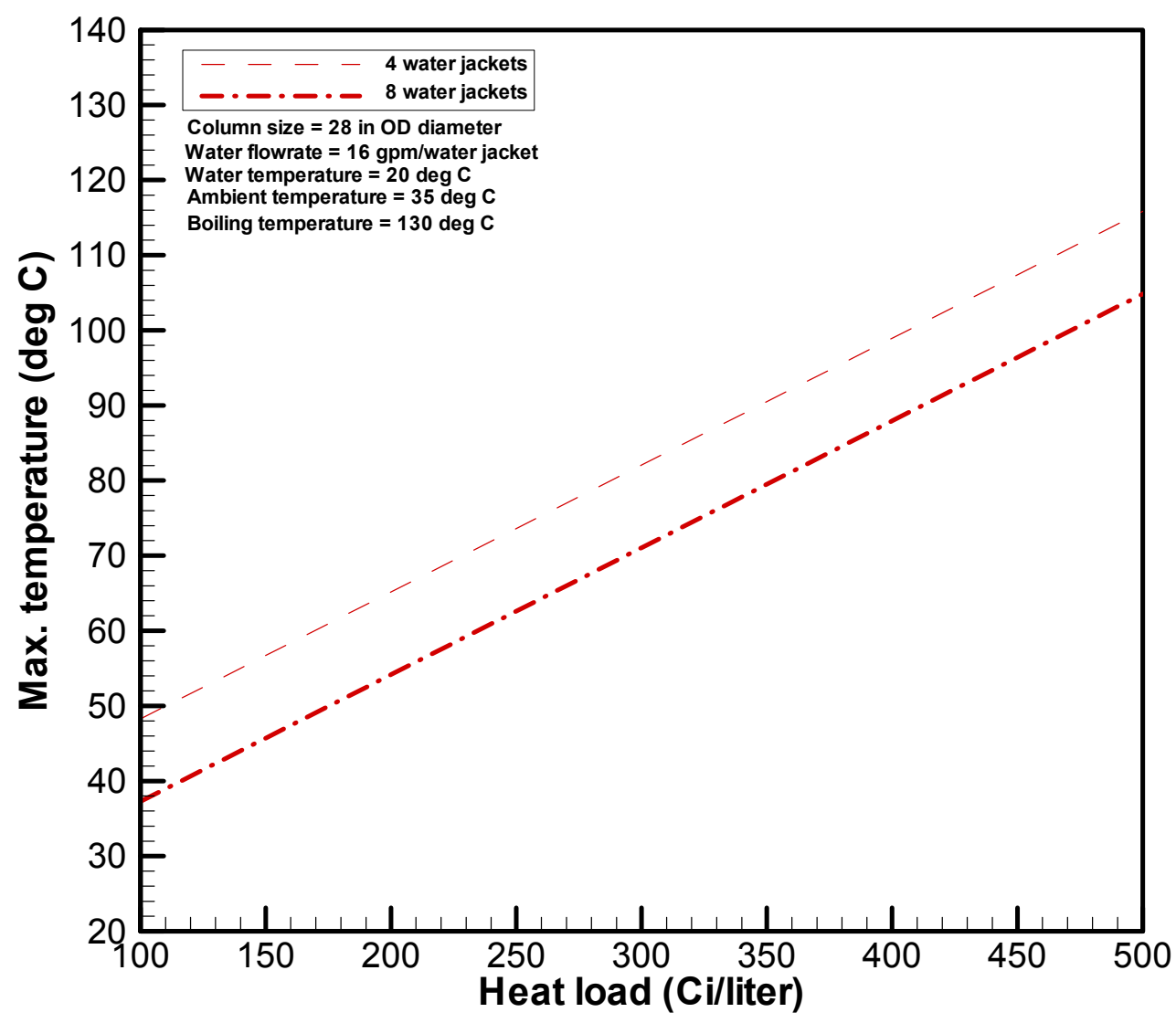

Figure 29. Steady-state maximum temperature as function of heat load for 28 -in column under the two design conditions of 4 and 8 water jackets 


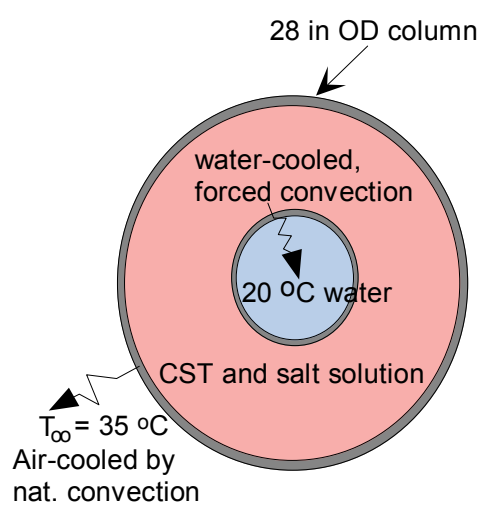

(column cooled by mixed convection)

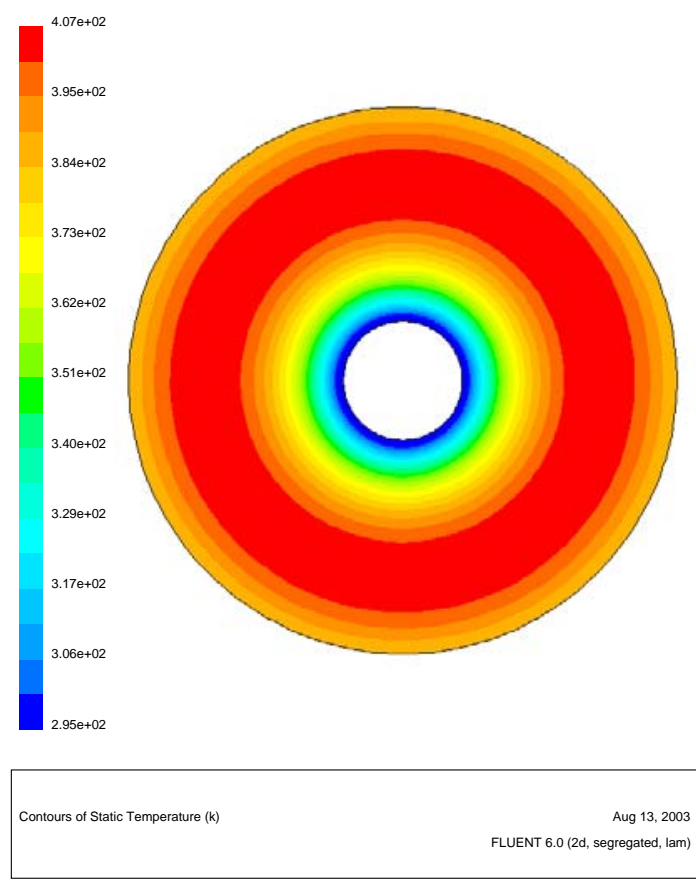

(column cooled by mixed convection)

$$
\begin{aligned}
& \mathrm{T}_{\max }=133.4^{\circ} \mathrm{C} \\
& \mathrm{T}_{\text {min }}=22.1{ }^{\circ} \mathrm{C}
\end{aligned}
$$

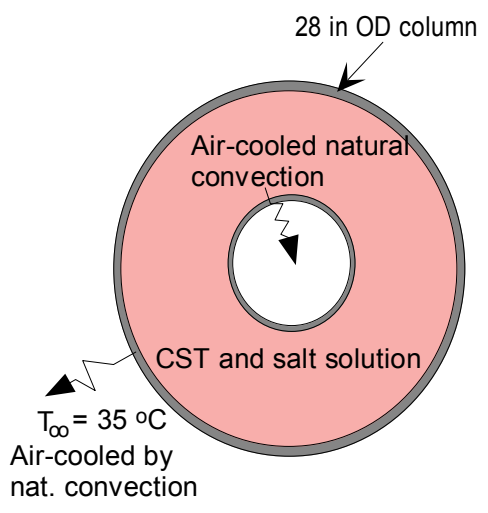

(column cooled by natural convection
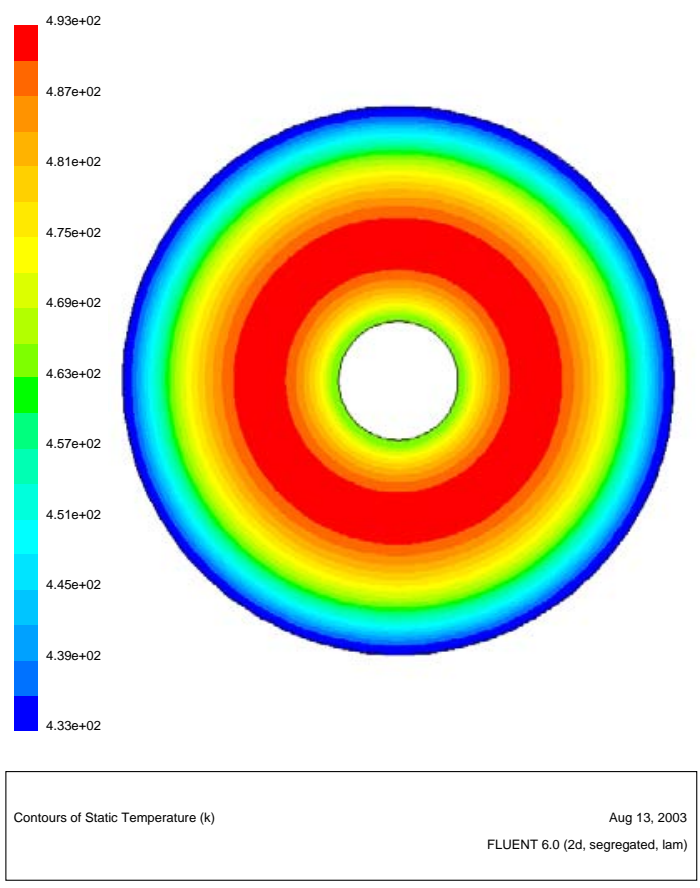

(column cooled by natural convection

$$
\begin{aligned}
& \mathrm{T}_{\text {max }}=220.3^{\circ} \mathrm{C} \\
& \mathrm{T}_{\text {min }}=159.5^{\circ} \mathrm{C}
\end{aligned}
$$

Figure 30. Comparison of temperature distributions between two different designs of 28in CST columns imbedded with 6-in pipe at its center (300 Ci/liter heat load) 

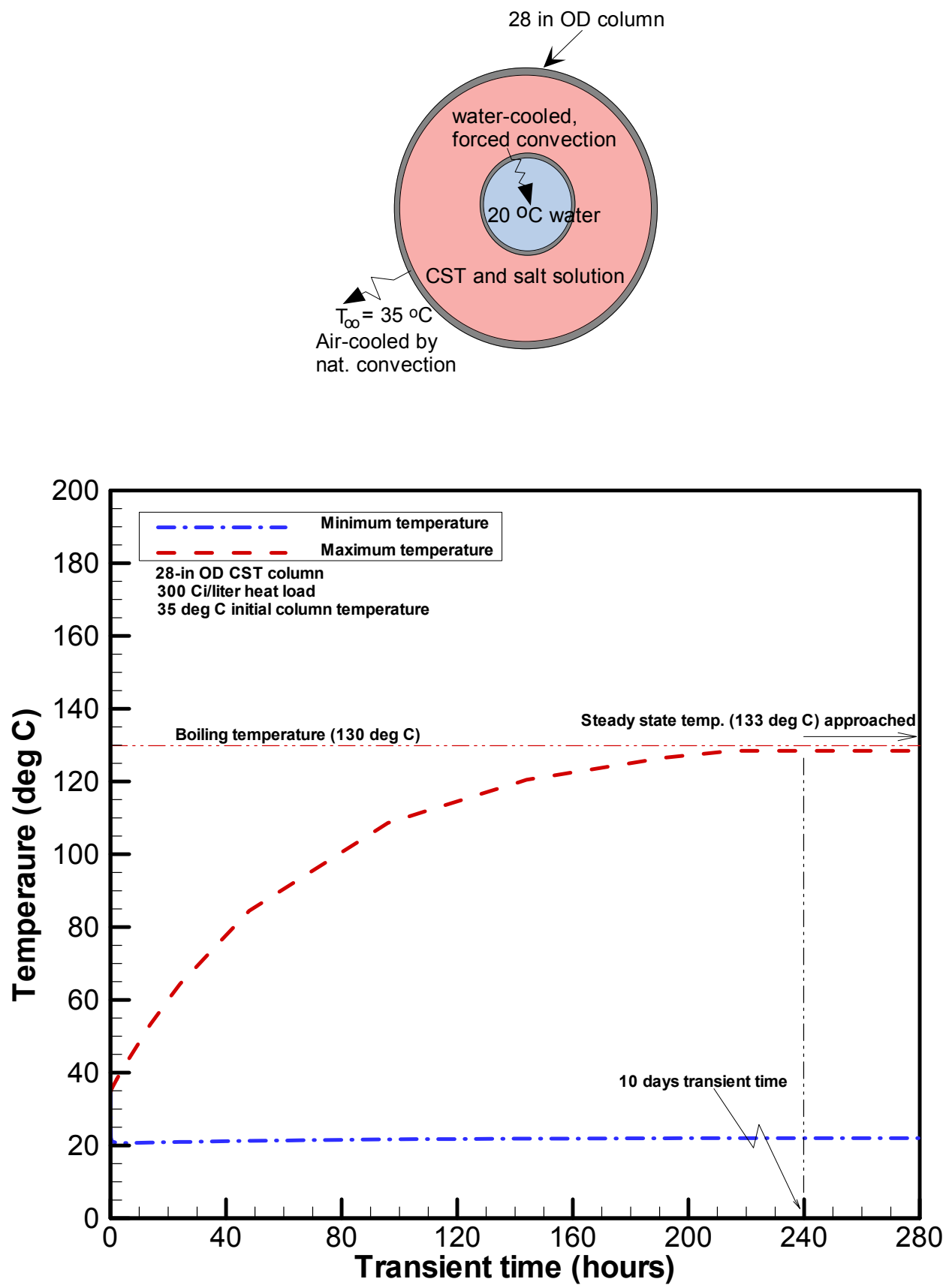

Figure 31. Transient temperature responses for 28-in column with $300 \mathrm{Ci} /$ liter heat load under the Case-b design conditions 

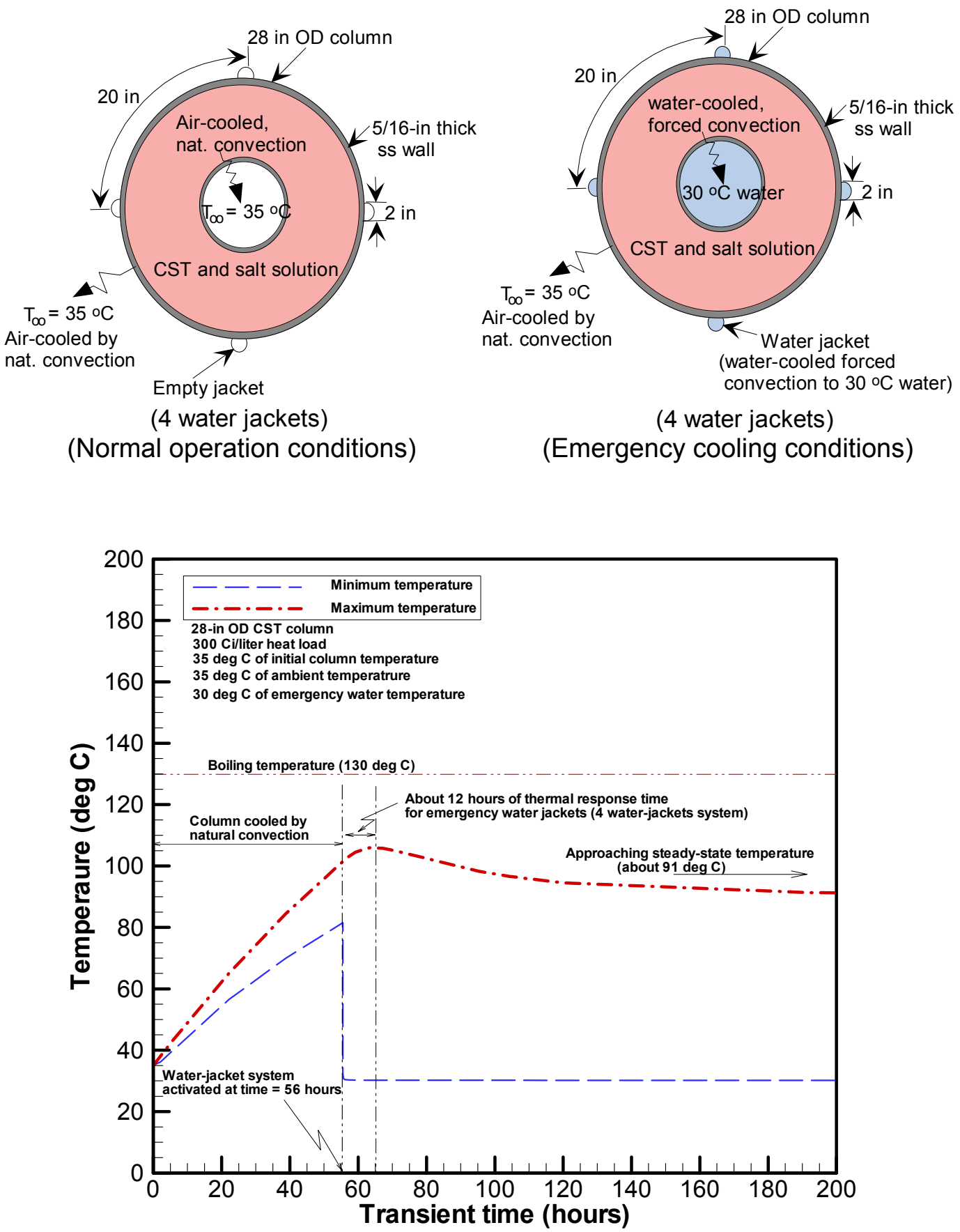

Figure 32. Transient temperatures for 28-in column loaded with $300 \mathrm{Ci} /$ liter under the Case-a design condition assuming that emergency water-jacket system is activated when maximum temperature of the CST column exceeds $100{ }^{\circ} \mathrm{C}$ 


\section{Conclusions}

Transient two-dimensional heat conduction calculations with modeling assumptions have been performed to assess how fast a CST ion exchange column heats up on loss of flow under the potential operating conditions and design geometries. In the present analysis, convection and radiation transport processes inside the CST column were assumed to be negligible compared to conduction heat transfer under no process flow conditions. The CST-salt solution column was assumed to be cooled by natural convection or mixed convection. A computational heat transfer approach was taken using Fluent ${ }^{\mathrm{TM}}$, a commercial computational fluid dynamics (CFD) code. In addition, the results computed by the present model were verified by the theoretical results.

The Case-I and Case-II models investigated steady-state and transient temperature profiles of the CST-salt solution system due to natural convection cooling and mixed convection and quantified the CST temperatures inside the cylindrical packed column containing a decay heat source for the no process flow situation. The Case-III and Case-IV models quantified the transient temperature responses of the system heatup for various design conditions and different cooling mechanisms of the CST-salt column system since the modeling results of the Case-I and Case-II designs show that peak temperature of the CST-salt solution system reaches undesirable boiling condition in case of no process flow. The transient results for the column cooled by mixed convection showed that $130^{\circ} \mathrm{C}$ maximum temperature of the column was reached about 10 days after the transient initiation of no flow conditions.

When emergency coolant systems are available during loss of flow accident, the transient results show that $100{ }^{\circ} \mathrm{C}$ maximum temperature of the $300 \mathrm{Ci} /$ liter loaded column was reached about 56 hours after the initiation of no flow conditions, and the temperature trend is reversed about 12 hours after the activation of the emergency water cooling system. Sensitivity analysis for the CST column was made to find out how sensitive to each of these parameters is the coolability of the column and to quantify their impact on the system cooling capability. The parameters studied here are the efficient column geometry, heat load, and cooling mechanism of the CST column with no process flow situation.

From the present analysis results, the main conclusions are made as follows:

- Under no process flow condition, the transient temperature response of the CST-salt column loaded with $300 \mathrm{Ci} /$ liter decay heat is slow. It takes about 4 days for a 20 -in column to reach boiling condition under the Case-I reference conditions.

- From the sensitivity study of the CST column parameters, it was found that water coolant system in the middle of the column is most effective in removing the column heat load under no flow conditions since an effective thermal boundary layer adjacent to the potential location of the peak temperature is formed by convective fluid motion.

- The analysis results indicated that the cooling mechanism at the column center has significant impact on maximum column temperature for the present configurations, compared to the cooling mechanism at the column boundary. Thus, the temperature difference between maximum and minimum temperatures of the column is reduced rapidly as cooling capability at the center of the column is enhanced. 
Report: WSRC-TR-2003-00416

Date: $\quad 12 / 8 / 2003$

Page: $\quad 50$ of 52
WESTINGHOUSE SAVANNAH RIVER COMPANY

HEAT TRANSFER ANALYSIS FOR A FIXED CST COLUMN

(This Page Intentionally Left Blank) 


\section{$6 \quad$ References}

1. E-mails on Column Design Information, D. D. Walker, July 29 and August 12 , 2003.

2. B. B. Spencer, H. Wang, K. K. Anderson, "Thermal Conductivity of IONSIVIE911TM Crystalline Silicotitanate and Savannah River Waste Simulant Solutions", ORNL/TM-2000/285, Oah Ridge National Laboratory, TN, 2000.

3. Fluent ${ }^{T M}$, Fluent, Inc. (1998).

4. S. Y. Lee, "Heat Transfer Calculations for a Fixed CST Bed Column", WSRC-TR2000-00522 (December 2000).

5. D. T. Bostick and W. V. Steele, "Thermal and Physical Property Determination for IonsivIE-911 Crystalline Silicotitanate and Savannah River Waste Simulant Solutions", WSRC-TR-99-00323, Rev. 0 (August 1999).

6. S. Y. Lee, "Heat Transfer Calculations for Normal Operations of a Fixed CST Bed Column", WSRC-TR-2001-00255 (May 2001).

7. W. M. Kays and M. E. Crawford, Convective Heat and Mass Transfer, Second Edition, McGraw-Hill Book Company, New York (1980).

8. J. P. Holman, Heat Transfer, $4^{\text {th }}$ edition, McGraw-Hill Book Company, New York (1976).

9. A. J. Chapman, Heat Transfer, Third Edition, Macmillan Publishing Co., Inc,, (1974).

10. C. Y. Warner and V. S. Arpaci, "An Experimental Investigation of Turbulent Natural Convection in Air at Low Pressure along a Vertical Heated Flat Plate", International Journal of Heat and Mass Transfer, Vol. 11, pp. 397-406 (1968).

11. J. Jerrell, S. Y. Lee, and A. Shadday, "Thermal Analysis of the Failed Equipment Storage Vault System (U)", WSRC-TR-95-0288 (1995).

12. R. Krupiczka, "Analysis of Thermal Conductivity in Granular Materials", International Chemical Engineering, Vol. 7, No. 1, pp. 122-144 (1967).

13. J. A. Pike and R. A. Jacobs, "Interoffice Memorandum: Input for Heat Transfer Calculations for a Fixed Bed CST Ion Exchange Column", HLW-SDT-2000-00456, Rev. 0, October 30, 2000.

14. W. M. Rohsenow and H. Y. Choi, Heat, Mass, and Momentum Transfer, PrenticeHall, Inc., New Jersey (1961).

15. F. W. Dittus and L. M. E. Boelter, Engineering Publication vol. 2, pp. 443, University of California (1930). 
Report: WSRC-TR-2003-00416

Date: $\quad 12 / 8 / 2003$

Page: 52 of 52
WESTINGHOUSE SAVANNAH RIVER COMPANY

HEAT TRANSFER ANALYSIS FOR A FIXED CST COLUMN

(This Page Intentionally Left Blank) 